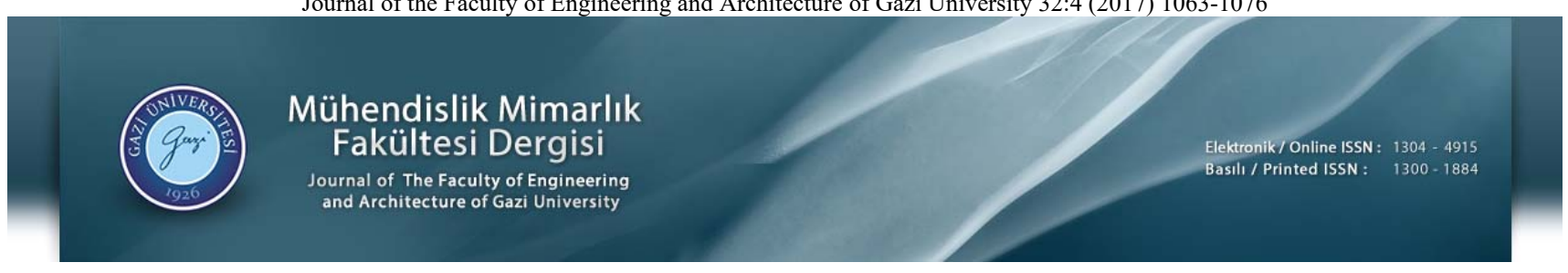

\title{
Türkiye'deki deniz dibi tarama malzemelerinin faydalı kullanım öncesi çevresel etkilerinin belirlenmesi: Ticari limanlar \& balıkçı barınakları
}

\author{
Hatice Merve Başar(D) 1*, Barıș Güzel(D)2, Pembe Özer Erdoğan (D)2, Leyla Tolun (D)2 \\ ${ }^{1}$ Sürdürülebilir Kalkınma ve Temiz Üretim Uygulama ve Araştırma Merkezi, Boğaziçi Üniversitesi, Bebek, 34342, İstanbul, Türkiye \\ ${ }^{2}$ Çevre ve Temiz Üretim Enstitüsü, TÜBİTAK Marmara Araştırma Merkezi, Gebze, Kocaeli, 41470, Türkiye
}

\section{Ö N E Ç I K A N L A R}

- Deniz dibi tarama malzemesinin çevresel etkileri

- Fiziko-kimyasal, toksikolojik ve sızma özellikleri

- Deniz dibi tarama malzemesinin faydalı kullanım alternatifleri ön değerlendirmesi

Makale Bilgileri

Geliș: 18.05.2016

Kabul: 06.04.2017

DOI:

10.17341/gazimmfd.369389

Anahtar Kelimeler:

Karakterizasyon,

dip tarama malzemesi,

çevresel etki,

faydalı kullanım

\section{ÖZET}

Bu çalışmada Türkiye'deki üç ticari liman ve dört balıkçı barınağından alınan deniz dip tarama malzemelerinin (DTM) faydalı kullanım öncesi çevresel etkilerinin araştıılması ele alınmıştır. İlk olarak, DTM'lerin fiziko-kimyasal, toksikolojik, sızma ve mineralojik özellikleri belirlenmiş ve tane boyutu dağılımları saptanmıştır. Sonrasında, çevresel analiz sonuçları "Atık Yönetimi Yönetmeliği-EK 3B" ve “Atıkların Düzenli Depolanmasına Dair Yönetmelik-EK2" limit değerleri ile kıyaslanmıştır. Ayrıca, DTM'lerin çeșitli faydalı kullanım alternatifleri için ön değerlendirmeleri yapılmıștır. Karakterizasyon sonuçları DTM'lerin tehlikesiz atık (atık kodu 1705 06) olarak tanımlanabileceğini ve II. Sınıf düzenli depolama sahalarında depolanabileceğini göstermiştir. Bu çalışmanın bulguları DTM'lerin fiziko-kimyasal özelliklerinin iyileştirilmesi durumunda zirai/ürün uygulamalarında (iyileştirilmiş yüzey toprağı, beton, karayolu dolgusu vb.) herhangi bir olumsuz çevresel etki olmaksızın faydalı bir șekilde kullanılabileceğini önermektedir. Ancak, her bir faydalı kullanım uygulamasında elde edilecek ürünler için teknik, çevresel, yasal ve ekonomik değerlendirme gerekmektedir.

\section{Determination of the environmental effects of Turkey's marine dredged materials prior to beneficial use: Commercial ports \& fishery harbours}

\section{H I G H L I G H T S}

- $\quad$ Environmental effects of maine dredged material

- Physico-chemical, toxicological and leaching properties

- Preevaluation of beneficial use alternatives of marine dredged material

Article Info

Received: 18.05 .2016

Accepted: 06.04.2017

DOI:

$10.17341 /$ gazimmfd.369389

Keywords:

Characterization, dredged material, environmental effect, beneficial use

\section{ABSTRACT}

In this study, the investigation of the environmental effetcs of the marine dredged materials (DMs) collected from three commercial ports and four fishery harbours of Turkey prior to beneficial use was undertaken. Firstly, physico-chemical, toxicological, leaching and mineralogical properties were determined for the qualification of DMs and grain size distributions were identified. Then, environmental analysis results were compared with the limit values stated in "The Waste Management Regulation-Appendix 3B" and "The Regulation on the Landfilling of Waste-Appendix 2". Besides, pre-evaluation of DTMs for several beneficial use alternatives was performed. Characterization results showed that DMs can be defined as "nonhazardous waste" (waste code 1705 06) and can be disposed at Class II landfills. The findings of this study suggest that DMs can be beneficially used in agricultural/product applications (i.e. manufactured topsoil, concrete, road fill) with no adverse environmental effects in case of some improvements on its physico-chemical properties. However, technical, environmental, legal and economic evalution is required for products to be manufactured at each benefical use application. 


\section{GİRIŞ (INTRODUCTION)}

1980'lerden bu yana Türk ekonomisi ve Türk dış ticareti hızlı bir büyüme sürecine girmiş olup, 2016 yılında Türk dış ticaret hacmi 341,1 milyon dolara yükselirken, ihracat/ithalat oranı \%71,8 olmuştur [1]. Denizcilikle gerçekleştirilen Türk dış ticareti 2016 yılında ithalatta \%60,6, ihracatta \%55,0 [1] ve toplamda 430,2 milyon tok yük [2] ile diğer ulaşım seçenekleri arasında en tercih edilen alternatif olmuştur $[1$, 2]. Günümüzde, deniz ulaşımının ve limanların rolü oldukça açıktır [3]; bu sebeple, gemi seyir yolları ve limanlardaki tarama faaliyetleri sürdürülebilirlik açısından gereklidir [4, 5]. Ülkemizde y1lda $\sim 3$ milyon $\mathrm{m}^{3}$ DTM çıkarılmakta olup mevcut durumda dökü gemileriyle açı denize boşaltılmaktadır, çok az bir kısmı ise bertaraf edilmektedir. Deniz çevresinin boşaltım kaynaklı kirliliğe karşı korunmasını sağlayan küresel bir anlaşma olan Londra Sözleşmesi'ne (1972) Türkiye'nin taraf olma süreci 2016 yılında başlamıştır [6]. Ülkemizin bölgesel sözleşmeler olan Barselona (1976) ve Bükreş (1992) Sözleșmelerinin ve Protokollerinin gerekliliklerini yerine getirme zorunluluğu olduğu halde DTM yönetimine ilişkin ulusal tek yasal mevzuat "Çevresel Etki Değerlendirmesi Yönetmeliği (ÇED)'dir ve ne yazık ki söz konusu Yönetmelik denize boşaltım alanlarının seçimi, izlenmesi ve denize boşaltım kriterlerinin belirlenmesi açısından yetersizdir [7]. Bu sebeple, ulusal ve bilimsel bazda DTM yönetimine ihtiyaç duyulmuştur. "(111G036) Deniz Dip Tarama Uygulamaları ve Tarama Malzemesinin Çevresel Yönetimi (DİPTAR)" isimli 3-y1llık ulusal araştırma projesi DTM'lerin denize boşaltım, bertaraf ve faydalı kullanım kapsamında entegre çevresel yönetimine sürdürülebilir yaklaşım geliştirmek üzere 01.10.2013-01.10.2016 tarihleri arasında yürütülmüştür. Ayrıca, projede DTM yönetimine yönelik ilk kez Yasal Mevzuat hazırlanması amacıyla Çevre ve Şehircilik Bakanlığı'na yeterli veri ve bilgi sağlanmıştır [8]. DTM Atık Çerçeve Direktifi (2008/98/EC)'nde 170505 (kirli sedimanlar) ve 170506 (diğer sedimanlar) kodları ile atık olarak tanımlanmaktadır [9]. Doğal kaynakların tükenme sınırında olduğu ve çeşitli ülkelerin sürdürülebilir kalkınma hedefleri düşünüldüğünde, DTM'lerin faydalı kullanımı pek çok alanda denize boşaltım/bertarafa göre daha çok önem kazanmıştır [10]. Denize boşaltım sucul ekosistemde fiziksel, kimyasal ve/veya biyolojik risklere sebep olmaktadır [11]; bertaraf ise maliyetlidir, geniş deponi alanlarına ihtiyaç vardır $[12,13]$ ve uzun dönem izleme gerekmektedir [14]. Faydalı kullanım DTM'yi potansiyel bir ürün olarak değerlendiren ve çevresel, ekonomik, sosyal avantajlar sağlayan bir prosestir [15]. Faydalı kullanım alternatifleri üç ana grupta toplanmaktadır [16]; a) mühendislik kullanımı (arazi reklamasyonu [17], kumsal beslenmesi [18], kıyı koruma, deponi sahası günlük ara örtü/geçirimsiz tabaka $[19,20])$; b) çevresel restorasyon (sulak alan oluşturma/iyileştirme [21], su ürünleri yetiştiriciliği [22] vb.) ve c) zirai/ürün kullanımı (yüzey toprağ $[23,24]$, karayolu dolgusu [10, 25], tuğla [26, 27], seramik [28, 29], hafif agrega [30, 31], hazır beton [32], beton parke taşı $[33,34]$, çimento $[35,36])$. Diğer yandan, yüksek miktarlarda DTM limanlardaki antropojenik faaliyetler sonucu kontamine olmaktadır. Kontaminasyon temel olarak organik ve inorganik kirleticilerden kaynaklanmaktadır. PAH (Poliaromatik Hidrokarbon), PCB (Poliklorlu Bifenil), Pestisit, PCDD/F (Dioksin/Furan) ve Tributilkalay yüksek toksisiteli organik kirleticiler olarak düşünülebilir. Ağır metaller (Kurşun $(\mathrm{Pb}), \operatorname{Krom}(\mathrm{Cr}), \mathrm{C}$ ıva $(\mathrm{Hg})$, Çinko (Zn), Kadmiyum (Cd), Bakır (Cu) vb.), Nitratlar, Fosfatlar ve tuzlar esas inorganik kirleticilerdir [14, 37]. Çeşitli araştırmacılar en uygun faydalı kullanım alternatifini seçebilmek için çalışmalarında sediman ve DTM'lerin (Fransa Dunkirk Limanı deniz sedimanı [10, 38], Tunus Rades ve Gabes Limanları deniz sedimanı [39], İrlanda deniz dibi tarama malzemesi [16], Malezya deniz sedimanı [40]) karakterizasyonunu ve dolayısıyla çevresel etkilerini incelemişlerdir. Ancak, Türkiye kıyılarındaki DTM'lerin detaylı çevresel karakterizasyonu, sedimanların aksine, daha önce çalışılmamıştır. Ülkemizde yapılan çalışmalar daha çok atıkların/toprakların çevresel etkilerinin belirlenmesi ve geri kazanımları/bertarafları yönünde olmuştur. $\mathrm{Bu}$ çalışmalara örnek olarak; atık fosfojipslerin yapı malzemesi olarak ekonomiye geri kazandırılması [41], atık cam ve yüksek firın cürufu katkılı harçların özellikleri [42], uçucu küllerin inşaat sektöründe kullanim potansiyeli [43], cam elyaf takviyeli polyester (CTP) boru üretim atığ ilaveli polivinilklorür (PVC) matriksli kompozit malzemelerin mekanik özelliklerinin incelenmesi [44], geri dönüşümlü iri agregaların beton özelliklerine etkisi [45], deri arıtma çamuru kompostu ilavesiye gerçekleştirilen çim yetiştiriciliğinde $\mathrm{Cr}, \mathrm{Cu}, \mathrm{Zn}$ ve $\mathrm{Ni}$ metallerinin kimyasal dağılımı ve bitkiye transferi [46], plazma gazlaştırma teknolojisi ile katı atık bertarafı [47], mikroalg üretimi ve mikroalglerden biyoyakıt eldesi [48], atık mineral yağ ile kirlenmiş topraklarda organik azot fraksiyonlarının belirlenmesi [49] ve Bursa'nın zeytinlik arazilerindeki topraklarda poliaromatik hidrokarbon (PAH) konsantrasyonlarının bölgesel değişimi [50] verilebilir. Uygun faydalı kullanım alternatifini seçmeden önce, DTM'lerin Ulusal Mevzuat'ımızdaki "Atık Yönetimi Yönetmeliği (AYY) (02.04.2015-R.G.29314)" ve “Atıkların Düzenli Depolanmasına Dair Yönetmelik (ADDDY) (26.03.2010-R.G.27533)"ye göre karakterizasyonlarının ve AYY-EK3B ile ADDDY-EK2 limit değerlerine uygunluklarının ortaya konulması önemlidir. Bu çalışmanın amacı, Türkiye'deki dört denizde yer alan üç ticari limandan ve dört balıkçı barınağından alınan DTM örneklerinin faydalı kullanım öncesi çevresel etkilerinin ve karakteristiklerinin belirlenmesi için fiziko-kimyasal, toksikolojik, sızma ve mineralojik özelliklerinin araştırılması ve zirai/ürün kullanımı gibi çeşitli faydalı kullanım alternatifleri için ön değerlendirmelerinin yapılmasıdır. Söz konusu çalışma zirai/ürün kullanım uygulamalarında çevresel açıdan ses getirecek faydalı kullanım alternatiflerinin ön tanımlanması konusunda DİPTAR Projesinin ilk fazıdır [8]. Ayrıca, sedimanlardan farklı olarak, ülkemizdeki deniz DTM'lerinin tüm çevresel etkilerini detaylıca araştıran bugüne kadarki ilk çalışmadır. Çalışmanın devamında, DIPTAR Projesi kapsamında 
DTM'lerin zirai/yapısal uygulamalarda (iyileştirilmiş yüzey toprağı, beton, agrega vb.) hammadde olarak kullanımına yönelik yürütülen geniş çaplı laboratuvar çalışmaları ve bulguları gelecek yayınlarla [23, 32] verilmeye devam edilecektir.

\section{MATERYAL VE YÖNTEM (MATERIAL AND METHOD)}

\subsection{Materyal (Material)}

Çalışmada kullanılan DTM'ler yükleme-boşaltma faaliyetleri ile bilinen üç ticari limandan (DTM-1, 2, 5) ve dört balıkçı barınağından (DTM-3, 4, 6, 7) taranmıştır. Pilot bölgeler Şekil 1'de, bu bölgelere ilişkin detay bilgiler Tablo 1'de verilmiştir. Tarama yapılacak alanı temsil etmesi ve taranacak malzemenin faydalı kullanım alternatiflerinin ileriki çalışmalarda araştırılması açısından, her bir pilot ticari liman/balıkçı barınağının iç kısımlarından $\sim 1 \mathrm{~m}^{3}$ DTM numunesi $8 \mathrm{~m}$ derinlikten kepçeli ve kovalı tarak gemisi ve ekskavatör ile alınmıştır. Kamyon ile TÜBİTAK MAM laboratuvarlarına taşınmış ve oda koşullarında $30 \mathrm{dm}^{3} \mathrm{lük}$ yüksek yoğunluklu Polietilen (HDPE) hermetik kaplarda stoklanmıştır. Laboratuvar ve pilot ölçekli faydalı kullanım alternatiflerinin araştırılması öncesinde DTM'lerden 5 kg'lık kompozit numuneler hazırlanarak çevresel etkiler detaylı araştırılmıştır.

\subsection{Yöntem (Method)}

\subsubsection{Fiziko-kimyasal ve mineralojik özellikler (Physico-chemical and mineralogical properties)}

DTM'lerin nem/katı madde içerikleri $105^{\circ} \mathrm{C}$ 'de kurutma ile, organik/inorganik madde içerikleri ise kül firınında $550^{\circ} \mathrm{C}$ 'de yakma ile saptanmıştır. $\mathrm{pH}$ ve iletkenlik değerleri WTW Inolab multimetre ile ölçülmüştür. DTM'lerin tane boyutu dağılımları yaş elek analizi ve hidrometre testi ile tespit edilmiştir. Metal ve anyon konsantrasyonlarının tespiti için sırasıyla Perkin-Elmer 8300 DV İndüktif Eşlenmiş Plazma-Optik Emisyon Spektroskopi (ICP-OES) ve Dionex

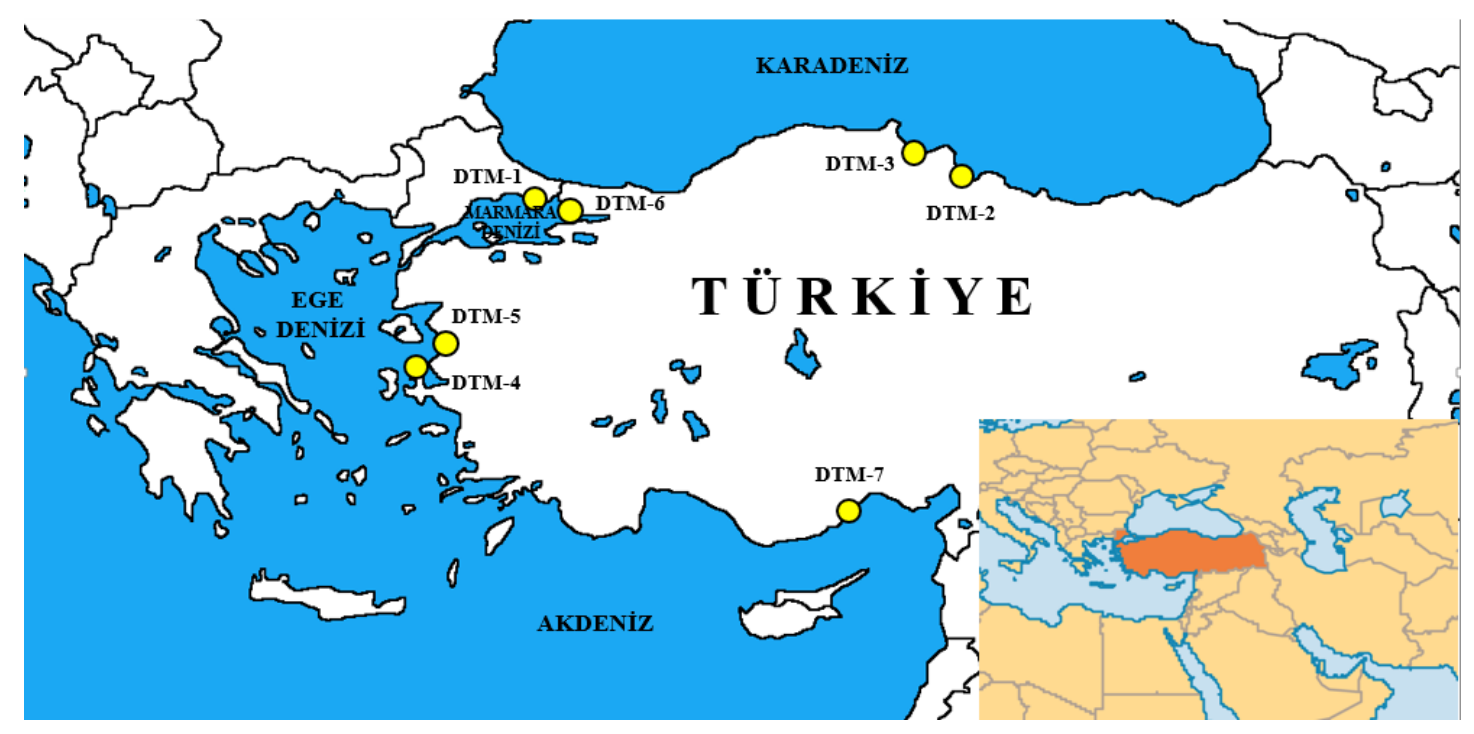

Şekil 1. Pilot bölgeler (Pilot regions)

Tablo 1. Pilot bölgelere ilişkin bilgiler (Information relating to pilot regions)

\begin{tabular}{|c|c|c|c|c|c|}
\hline Örnek No & Pilot Bölge & Deniz Ad1 & Koordinatlar & Tarih & Tarayıcı Türü \\
\hline DTM-1 & $\begin{array}{l}\text { İstanbul Ambarlı } \\
\text { Limanı }\end{array}$ & $\begin{array}{l}\text { Marmara } \\
\text { Denizi }\end{array}$ & $\begin{array}{l}40^{\circ} 57^{\prime} 44^{\prime \prime} \mathrm{N} \\
28^{\circ} 40^{\prime} 37^{\prime \prime} \mathrm{E}\end{array}$ & 20.02 .2014 & Kovalı tarak gemisi \\
\hline DTM-2 & Samsun Limanı & Karadeniz & $\begin{array}{l}41^{\circ} 18^{\prime} 01^{\prime \prime} \mathrm{N} \\
36^{\circ} 20^{\prime} 40^{\prime \prime} \mathrm{E}\end{array}$ & 27.05 .2014 & Kepçeli tarak gemisi \\
\hline DTM-3 & $\begin{array}{l}\text { Samsun Yakakent } \\
\text { Balıkçı Barınağ1 }\end{array}$ & Karadeniz & $\begin{array}{l}41^{\circ} 38^{\prime} 22^{\prime \prime} \mathrm{N} \\
35^{\circ} 30^{\prime} 23^{\prime \prime} \mathrm{E}\end{array}$ & 28.05 .2014 & Kepçeli tarak gemisi \\
\hline DTM-4 & $\begin{array}{l}\text { İzmir Karaburun } \\
\text { Balıkçı Barınağ } 1\end{array}$ & Ege Denizi & $\begin{array}{l}36^{\circ} 40^{\prime} 17^{\prime \prime} \mathrm{N} \\
26^{\circ} 26^{\prime} 18^{\prime \prime} \mathrm{E}\end{array}$ & 20.06 .2014 & Kepçeli tarak gemisi \\
\hline DTM-5 & $\begin{array}{l}\text { İzmir PETKIMM } \\
\text { Konteyner Limanı }\end{array}$ & Ege Denizi & $\begin{array}{l}38^{\circ} 46^{\prime} 43^{\prime \prime} \mathrm{N} \\
26^{\circ} 55^{\prime} 44^{\prime \prime} \mathrm{E}\end{array}$ & 09.07 .2014 & Kovalı tarak gemisi \\
\hline DTM-6 & $\begin{array}{l}\text { Kocaeli Eskihisar } \\
\text { Balıķı Barınăgı }\end{array}$ & $\begin{array}{l}\text { Marmara } \\
\text { Denizi }\end{array}$ & $\begin{array}{l}40^{\circ} 46^{\prime} 08^{\prime \prime} \mathrm{N} \\
29^{\circ} 25^{\prime} 40^{\prime \prime} \mathrm{E}\end{array}$ & 24.09 .2014 & Kepçeli tarak gemisi \\
\hline DTM-7 & $\begin{array}{l}\text { Mersin Erdemli } \\
\text { Balıkçı Barınağ1 }\end{array}$ & Akdeniz & $\begin{array}{l}36^{\circ} 36^{\prime} 19^{\prime \prime} \mathrm{N} \\
34^{\circ} 19^{\prime} 19^{\prime \prime} \mathrm{E}\end{array}$ & 29.09 .2014 & Ekskavatör \\
\hline
\end{tabular}


ICS-1000 İyon Kromatografi kullanılmıştır. (Uçucu) organik bileşikler Fourier Dönüşümlü Infrared Spektroskopi (FT-IR) ve Headspace Gaz Kromatografi-Kütle Spektrometresi (GCMS) ile analiz edilmiştir. PCDD/F, PAH, Toplam Pestisit ve Tributilkalay konsantrasyonları sirasıyla Gaz KromatografiYüksek Çözünürlüklü Kütle Spektrometre (GC-HRMS), GC-MS ve Siv1 Kromatografi-Kütle Spektrometre-Kütle Spektrometre (LC-MSMS) kullanılarak belirlenmiştir. Üst Is1l Değer ve Toplam Kükürt (TS) içerikleri LECO-AC350 bomba kalorimetre ve LECO Truspec elementel analizör ile ölçülmüştür. Toplam Azot (TN), Toplam Fosfor (TP) ve Yağ-Gres içerikleri için Standard Metodlar [51] kullanılmıştır. Örneklerin mineralojileri Shimadzu marka XRD-6000 model X-Işını Difraktometre (XRD) ile Cu-k $\alpha$ 1Şıması $\left(\lambda=1.5405^{\circ} \mathrm{A}\right)$ kullanılarak aydınlatılmıştır.

\subsubsection{Toksikolojik özellikler (Toxicological properties)}

DTM'lerin ekotoksikolojik özellikleri için balık ve farelerde akut toksisite testleri gerçekleştirilmiştir. 24 saat ekstrakte edilen DTM'lerde (L/S: 10 L/kg), ISO/EN/DIN 11348'e uygun olarak ToxAlert 100 cihazı kullanılarak biyoluminesans bakteri (Vibrio fischeri) [52] ile ekotoksisite analizi yapılmıştır. DTM'lerin 1/10 seyreltik sulu çözeltileri 92/69/EEC Metod C.1. Balıklarda Akut Toksisite-Zehirlilik Seyreltme Faktörü" testine tabi tutulmuş, test 1 L sulu çözeltide 2 adet tatlı su balığı (Lepistes Reticulates) ile 96 saat süresince gerçekleştirilmiştir. Balıklar test öncesi havalandırılmış, klorsuz içme suyu bulunan ve su sirkülasyonlu akvaryumda $20^{\circ} \mathrm{C}^{\prime} \mathrm{de}$ en az 48 saat bekletilmiştir. DTM'lerin akut oral toksisite testleri OECD TG423 kullanılarak, "TÜBITTAK Hayvan Deneyleri Yerel Etik Kurulu"ndan alınan etik belgesine uygun olarak 3 adet laboratuvar faresi $B A L B / c$ (erkek) (8-12 haftalık) üzerinde yürütülmüştür. Test öncesi fareler 5 gün kafeste $22 \pm 3^{\circ} \mathrm{C}$ 'de, \%30-70 nemde, 12 saat aydınlık-12 saat karanlıkta laboratuvar diyeti ve sınırsız su ile bekletilmiştir. DTM'lerin $1 / 10$ seyreltik sulu çözeltileri $1 \mathrm{ml} / 100 \mathrm{mg}$ v.a dozunda gavaj ile farelere uygulanmış, klinik gözlem ve gross patolojik incelemeye tabii tutulmuştur. DTM'lerin zararlılık sınıfları BM Kimyasalların Sınıflandırılması ve Etiketlenmesi: Kısım 3.1'e göre belirlenmiştir.

\subsubsection{Stzma işlemi (Leaching procedure)}

DTM'lerdeki olası kirleticilerin eluata geçme özelliğinin belirlenmesi ve DTM'lerin uygun depolanabilirlik sınıflarının tespiti TS EN 12457-4 [53] sızma testi yöntemine göre araştırılmıştır. Buna göre, partikül boyutu L/S:10/1 su ile hazırlanan DTM'ler 24 saat çalkalanarak özütlenmiş, sıvı faz filtreden süzülmüştür. Metaller, anyonlar, Fenol ve Çözünmüş Organik Karbon (ÇOK) eluatta; PCB, BTEX (Benzen, Toluen, Etilbenzen, Ksilen), Toplam Organik Karbon (TOK) ve Hidrokarbonlar katıda ölçülmüştür. TOK and ÇOK analizleri TOC-V CPH Shimadzu cihazında yürütülmüş, Toplam Çözünen Katı Madde (TÇKM) içeriği gravimetrik olarak belirlenmiştir.

\subsubsection{Kalite güvence (Quality assurance)}

Eluat ve katı faz analizlerinde, IQC-026 ağır metal kalite kontrol standardı (Ultra Scientific, USA), Florür $\left(\mathrm{F}^{-}\right)$, Klorür $\left(\mathrm{Cl}^{-}\right)$, Sülfat $\left(\mathrm{SO}_{4}^{-2}\right)$ standart çözeltileri (Ultra Scientific, USA), TÇKM ve Fenol analitik referans malzemeleri (NIST, USA), pH 4 ve 7 tampon çözeltileri (Merck, Almanya), İletkenlik, TP ve TN kalite kontrol standardları (NIST, USA), D(+)-glikoz anhidrit TOK ve ÇOK standart çözeltileri (Merck, Almanya), BTEX, PCB, Pestisit ve uçucu organikler kalibrasyon standard çözeltileri (Absolute Std, USA; Dr. Ehrenstorfer GmbH, Almanya), Hidrokarbon kalite kontrol standardı (Accu Std, USA) ve PAH sertifikalı referans malzemesi CRM524 (EC BCR, Belçika) kalite kontrol amaçlı periyodik olarak kullanılmıştır. Her numune için analizler üç tekrarlı gerçekleştirilmiş ve $\% 95$ güven aralığında ortalama değerler standart sapmalar ile birlikte verilmiştir.

\section{SONUÇLAR VE TARTIŞMALAR (RESULTS AND DISCUSSIONS)}

\subsection{Atık Yönetimi Yönetmeliği - EK3B'ye Göre \\ Değerlendirme(Evaluation According To The Waste Management Regulation - Appendix 3B)}

DTM'lerin fiziko-kimyasal ve toksikolojik analiz sonuçları "AYY-EK3B: Tehlikeli atık eşik konsantrasyonları" ile kıyaslanmış [54] ve Tablo 2'de verilmiştir. DTM'lerin genellikle (koyu) gri renkte oldukları ve geçmişteki evsel atıksu deşarjlarından kaynaklı olası kirlilikler sebebiyle hafif kokulu oldukları (bakteri kaynaklı koku) saptanmıştır. DTM'ler düşük-orta nem içerikli (24,00-40,35\%) olup, yapılarında $\mathrm{CaCO}_{3}$ kaynağı olarak bilinen deniz kabukları mevcudiyetinden dolayı ve deniz suyunun doğal $\mathrm{pH}$ aralığının 7,5-8,5 olması sebebiyle (hafif) bazik (pH: 8,169,38) karakterdedirler. İletkenlik değerlerinin (1,86-4,08 $\mathrm{mS} / \mathrm{cm}$ ) (kısmen) yüksek olması, içerdikleri tuzluluk sebebiyle kabul edilebilir seviyelerdedir. Özgül ağırlıkları 2,240-2,643 $\mathrm{g} / \mathrm{cm}^{3}$ olup içerdikleri safsızlıklar sebebiyle silika kumununkinden $\left(2,650 \mathrm{~g} / \mathrm{cm}^{3}\right)$ daha düşüktür. DTM örneklerinin düşük organik içeriğe $(<0,01-5,84 \%)$, düşük Is1l Değer $(\sim 10,0 \mathrm{kcal} / \mathrm{kg})$ ve düşük Yağ-Gres içeriğine $(<180,0$ $405,0 \mathrm{mg} / \mathrm{kg}$ ) sahip oldukları gözlenmiş; inorganik karakterde oldukları tespit edilmiştir. DTM-2, DTM-3 ve DTM-6 örnekleri uzun yıllar evsel atıksu deşajına maruz kaldıkları halde, bu numunelerin fizikokimyasal yapıları organik içeriklerinin zamanla ayrıştığını göstermiştir. Ayrışmanın; DTM örneklerinin alındığı alanın yapısından, akıntı hızı ve bakteri faaliyetlerinden kaynaklanmış olabileceği düşünülmüştür. DTM'ler orta düzeyde TN $(80,0$ $994,9 \mathrm{mg} / \mathrm{kg})$ ve TP $(280,0-469,6 \mathrm{mg} / \mathrm{kg})$ içermektedirler [55]; ancak, DTM-5 kodlu numunedeki görece yüksek TP içeriği $(1.347,0 \mathrm{mg} / \mathrm{kg})$ olası deniz kirliliğini işaret etmektedir. DTM'lerin Headspace GC-MS analizinde ve hekzan ile ekstrakte edilmiş organik fazlarında gerçekleştirilen FT-IR analizleri neticesinde, örneklerde kaydadeğer bir uçucu organik içeriğe ve fonksiyonel gruba rastlanmamıştır. Örnekleme (tarama) işlemi sırasında DTM'lerdeki uçucu organik bileşiklerin desorbe olarak su 
Tablo 2. DTM'lerin fiziko-kimyasal ve toksikolojik özellikleri (Physico-chemical and toxicological properties of DTMs)

\begin{tabular}{|c|c|c|c|c|c|c|c|c|}
\hline Parametreler & DTM-1 & DTM-2 & DTM-3 & DTM-4 & DTM-5 & DTM-6 & DTM-7 & Yöntem \\
\hline \multicolumn{9}{|c|}{ Fiziksel Özellikler } \\
\hline Renk & Füme & Füme & Füme & Gri & K.rengi & Füme & Gri & Görsel \\
\hline Koku & \multicolumn{3}{|c|}{ Hafif kokulu } & $\begin{array}{l}\text { Koku } \\
\text { yok }\end{array}$ & \multicolumn{3}{|c|}{ Hafif kokulu } & Duyusal \\
\hline Nem (\%ağ.) & $\begin{array}{l}26,15 \\
(0,34)\end{array}$ & $\begin{array}{l}40,35 \\
(0,52)\end{array}$ & $\begin{array}{l}29,53 \\
(0,38)\end{array}$ & $\begin{array}{l}25,99 \\
(0,34)\end{array}$ & $\begin{array}{l}24,00 \\
(0,31)\end{array}$ & $\begin{array}{l}32,01 \\
(0,42)\end{array}$ & $\begin{array}{l}30,59 \\
(0,40)\end{array}$ & $\begin{array}{l}\text { TS } 9546 \text { EN } \\
12880\end{array}$ \\
\hline $\begin{array}{l}\text { Kat1 Madde } \\
\text { (\%ağ.) }\end{array}$ & $\begin{array}{l}73,85 \\
(0,96)\end{array}$ & $\begin{array}{l}59,65 \\
(0,78)\end{array}$ & $\begin{array}{l}70,47 \\
(0,92)\end{array}$ & $\begin{array}{l}74,01 \\
(0,96)\end{array}$ & $\begin{array}{l}76,00 \\
(0,99)\end{array}$ & $\begin{array}{l}67,99 \\
(0,88)\end{array}$ & $\begin{array}{l}69,41 \\
(0,90)\end{array}$ & $\begin{array}{l}\text { TS } 9546 \text { EN } \\
12880\end{array}$ \\
\hline pH (sulu çöz.) & $\begin{array}{l}9,38 \\
(0,06)\end{array}$ & $\begin{array}{l}8,91 \\
(0,06)\end{array}$ & $\begin{array}{l}8,77 \\
(0,06)\end{array}$ & $\begin{array}{l}8,16 \\
(0,05)\end{array}$ & $\begin{array}{l}8,92 \\
(0,06)\end{array}$ & $\begin{array}{l}8,62 \\
(0,06)\end{array}$ & $\begin{array}{l}8,89 \\
(0,06)\end{array}$ & $\begin{array}{l}\text { TS } 8753 \text { EN } \\
12176\end{array}$ \\
\hline $\begin{array}{l}\mathrm{EC}(\mathrm{mS} / \mathrm{cm}) \\
\text { (sulu çöz.) }\end{array}$ & $\begin{array}{l}2,28 \\
(0,05)\end{array}$ & $\begin{array}{l}2,70 \\
(0,06)\end{array}$ & $\begin{array}{l}1,86 \\
(0,04)\end{array}$ & $\begin{array}{l}4,08 \\
(0,09)\end{array}$ & $\begin{array}{l}3,76 \\
(0,08)\end{array}$ & $\begin{array}{l}2,27 \\
(0,05)\end{array}$ & $\begin{array}{l}3,48 \\
(0,08)\end{array}$ & SM-2510 B \\
\hline $\begin{array}{l}\text { Özgül Ağırlık } \\
(\mathrm{g} / \mathrm{cm} 3)\end{array}$ & $\begin{array}{l}2,64 \\
(0,03)\end{array}$ & $\begin{array}{l}2,51 \\
(0,03)\end{array}$ & $\begin{array}{l}2,24 \\
(0,03) \\
\end{array}$ & $\begin{array}{l}2,38 \\
(0,03) \\
\end{array}$ & $\begin{array}{l}2,47 \\
(0,03)\end{array}$ & $\begin{array}{l}2,31 \\
(0,03)\end{array}$ & $\begin{array}{l}2,54 \\
(0,03)\end{array}$ & $\begin{array}{l}\text { TS EN 1097- } \\
6: 2002\end{array}$ \\
\hline \multicolumn{9}{|c|}{ Kimyasal Özellikler } \\
\hline $\begin{array}{l}\text { Organik } \\
\text { madde (\%ağ.) }\end{array}$ & $\begin{array}{l}2,26 \\
(0,01)\end{array}$ & $\begin{array}{l}2,91 \\
(0,01)\end{array}$ & $\begin{array}{l}2,46 \\
(0,01)\end{array}$ & $\begin{array}{l}5,84 \\
(0,03)\end{array}$ & $\begin{array}{l}5,01 \\
(0,02)\end{array}$ & $<0,01$ & $\begin{array}{l}1,18 \\
(0,01)\end{array}$ & TS 8336 \\
\hline $\begin{array}{l}\text { İnorganik } \\
\text { madde (\%ă̆.) }\end{array}$ & $\begin{array}{l}71,59 \\
(0,47)\end{array}$ & $\begin{array}{l}56,75 \\
(0,37)\end{array}$ & $\begin{array}{l}68,01 \\
(0,45)\end{array}$ & $\begin{array}{l}68,17 \\
(0,45)\end{array}$ & $\begin{array}{l}70,99 \\
(0,47)\end{array}$ & $\begin{array}{l}67,99 \\
(0,45)\end{array}$ & $\begin{array}{l}68,23 \\
(0,45)\end{array}$ & TS 8336 \\
\hline $\begin{array}{l}\text { Üst 1s1l değer } \\
(\mathrm{kcal} / \mathrm{kg})\end{array}$ & $\begin{array}{l}8,0 \\
(2,0)\end{array}$ & $\begin{array}{l}7,0 \\
(1,9)\end{array}$ & $\begin{array}{l}9,0 \\
(2,0)\end{array}$ & $\begin{array}{l}11,0 \\
(2,0)\end{array}$ & $\begin{array}{l}8,0 \\
(2,0)\end{array}$ & $\begin{array}{l}9,0 \\
(2,0)\end{array}$ & $\begin{array}{l}12,0 \\
(2,0)\end{array}$ & $\begin{array}{l}\text { ASTM D } \\
5865-13\end{array}$ \\
\hline $\mathrm{TS}(\%)$ & $\begin{array}{l}0,06 \\
(0,01)\end{array}$ & $\begin{array}{l}0,53 \\
(0,09)\end{array}$ & $\begin{array}{l}0,13 \\
(0,02)\end{array}$ & $\begin{array}{l}0,99 \\
(0,16)\end{array}$ & $\begin{array}{l}0,19 \\
(0,03)\end{array}$ & $\begin{array}{l}1,34 \\
(0,22)\end{array}$ & $\begin{array}{l}0,07 \\
(0,01)\end{array}$ & ASTM D4239 \\
\hline $\mathrm{TN}(\mathrm{mg} / \mathrm{kg})$ & $\begin{array}{l}113,6 \\
(3,9)\end{array}$ & $\begin{array}{l}731,4 \\
(25,1)\end{array}$ & $\begin{array}{l}400,4 \\
(13,7)\end{array}$ & $\begin{array}{l}174,1 \\
(6,0)\end{array}$ & $\begin{array}{l}80,2 \\
(2,8)\end{array}$ & $\begin{array}{l}994,9 \\
(34,1)\end{array}$ & $\begin{array}{l}354,5 \\
(12,2)\end{array}$ & SM-4500 N \\
\hline $\mathrm{TP}(\mathrm{mg} / \mathrm{kg})$ & $\begin{array}{l}397 \\
(10)\end{array}$ & $\begin{array}{l}717 \\
(18)\end{array}$ & $\begin{array}{l}470 \\
(12)\end{array}$ & $\begin{array}{l}280 \\
(7)\end{array}$ & $\begin{array}{l}1.347 \\
(34)\end{array}$ & $\begin{array}{l}398 \\
(10)\end{array}$ & $\begin{array}{l}320 \\
(8)\end{array}$ & SM-4500 P \\
\hline $\begin{array}{l}\text { Yağ-Gres } \\
(\mathrm{mg} / \mathrm{kg})\end{array}$ & $<180$ & $<180$ & $\begin{array}{l}405 \\
(29)\end{array}$ & $<180$ & $<180$ & $<180$ & $<180$ & SM-5220B \\
\hline $\begin{array}{l}\mathrm{PCDD} / \mathrm{F}(\mathrm{ng} / \mathrm{kg} \\
\mathrm{I} \text {-TEQ) }\end{array}$ & $\begin{array}{l}0,030 \\
(0,003)\end{array}$ & $\begin{array}{l}0,032 \\
(0,003)\end{array}$ & $\begin{array}{l}0,006 \\
(0,001)\end{array}$ & $<0,001$ & $\begin{array}{l}0,034 \\
(0,003)\end{array}$ & $\begin{array}{l}0,365 \\
(0,033)\end{array}$ & $\begin{array}{l}0,049 \\
(0,004)\end{array}$ & EPA 1613 \\
\hline PAH (mg/kg) & $\begin{array}{l}0,098 \\
(0,006)\end{array}$ & $\begin{array}{l}0,347 \\
(0,021)\end{array}$ & $\begin{array}{l}0,155 \\
(0,009)\end{array}$ & $\begin{array}{l}0,085 \\
(0,005)\end{array}$ & $\begin{array}{l}0,732 \\
(0,045)\end{array}$ & $\begin{array}{l}0,067 \\
(0,004)\end{array}$ & $\begin{array}{l}0,114 \\
(0,007)\end{array}$ & ISO 11338-2 \\
\hline $\begin{array}{l}\text { T. Pestisit } \\
(\mathrm{mg} / \mathrm{kg})\end{array}$ & $<0,005$ & $\begin{array}{l}0,025 \\
(0,003)\end{array}$ & $<0,005$ & $<0,005$ & $<0,005$ & $<0,005$ & $<0,005$ & $\begin{array}{l}\text { EPA } 8081 \text { ve } \\
8141\end{array}$ \\
\hline $\begin{array}{l}\text { Tributilkalay } \\
(\mathrm{mg} / \mathrm{kg})\end{array}$ & $<0,009$ & $<0,009$ & $<0,009$ & $<0,009$ & $<0,009$ & $<0,009$ & $<0,009$ & LC-MSMS \\
\hline \multicolumn{9}{|c|}{ Toksikolojik Özellikler } \\
\hline Ekotoksisite & \multicolumn{7}{|c|}{ Deniz bakterisi Vibrio fischeri [32] üzerinde ekotoksik değil. } & $\begin{array}{l}\text { ISO/EN/DIN } \\
11348\end{array}$ \\
\hline $\begin{array}{l}\text { Akut toksisite } \\
\text { (balık,) }\end{array}$ & \multicolumn{7}{|c|}{ Balıklar (Lepistes Reticulates) için akut risk yoktur. } & $\begin{array}{l}\text { 92/69/EEC- } \\
\text { C. } 1 .\end{array}$ \\
\hline $\begin{array}{l}\text { Akut toksisite } \\
\text { (fare) }\end{array}$ & \multicolumn{7}{|c|}{$\begin{array}{l}B A L B / c \text { faresi; Kategori } 5 \text { veya tanımlanmamış } \\
\left(\mathrm{LD}_{50}>5000 \mathrm{mg} / \mathrm{kg} \text { v.a. }\right)\end{array}$} & $\begin{array}{l}\text { OECD TG } \\
423\end{array}$ \\
\hline
\end{tabular}

kolonu üzerine çıktıkları andan itibaren havada uçucu hale gelmeleri olasıdır [56]. FT-IR ve GC-MS sonuçları DTM'lerin düşük organik içeriklerini doğrular niteliktedir. Diğer taraftan, PCDD/F, PAH, PCB ve Toplam Pestisitler gibi kalıcı organik kirleticiler için konsantrasyonlar sırayla 0,0011-0,3650 ng/kg I-TEQ, 0,009-0,732 mg/kg, <0,1-0,5 $\mathrm{mg} / \mathrm{kg}$ ve $<0,005 \mathrm{mg} / \mathrm{kg}$ olup şu şekilde sinıflandırılmaktadırlar; kanserojen kategori (Kans.Kat.) 3: R40 (H7), Kans.Kat.1,2: R45 (H7), üreme yetisini azaltıc1 kategori (Üre.Kat.) 1,2: R61 (H10), Xn: R20/21/22 (H5), Xi (R36/37/38) (H4), N: R50/53 (H14) ve ilgili eşik konsantrasyonları $\% 1 ; \% 0,1 ; \% 0,5 ; \% 25 ; \% 20 ; \% 0,25$ dir $[54,57]$. Bu kirleticiler için en kötü eşik konsantrasyon senaryosu düşünüldüğünde, limit altında oldukları görülmektedir. DTM'lerin organik madde içeriği bakımından "AYY-EK 3B"ye göre tehlikesiz özellik gösterdikleri tespit edilmiştir. DTM'lerin denizel ortam bakterisi Vibrio fischeri [52] üzerinde ekotoksik etki göstermedikleri, tatlı su balığı Lepistes Reticulates ve laboratuvar faresi $B A L B / c$ (erkek fare) için ise herhangi bir akut risk oluşturmadıkları ve balık/fare ölümüne sebebiyet vermedikleri belirlenmiştir; ancak, olası kronik etkiler bu 
çalışma kapsamında ele alınmamıştır. Bununla birlikte, Tablo 3'te verilen tane boyutu dağılımlarına göre, DTM'lerin genel olarak ince ve kaba kum ile birlikte bir miktar silt ve kilden oluştuğu tespit edilmiştir. DTM'ler kum kaynağ1 malzemeler olarak düşünülebilir. DTM'lerin asit ile parçalama sonrası ICP-OES (ISO 11885, EPA 7473) ile belirlenen ağır metal içerikleri DTM-1, DTM-2, DTM-3 ve DTM-4 kodlu numuneler için Tablo 4'te, DTM-5, DTM-6 ve DTM-7 kodlu numuneler için Tablo 5'te verilmiş olup AYY-EK3B kriterleri açısından herhangi bir çevresel risk teşkil etmeyecek düzeyde oldukları tespit edilmiştir [54, 57].DTM'lerin XRD-Rietveld ile belirlenen kantitatif faz analiz sonuçları ise Tablo 6'da verilmiştir. Mineralojik analiz sonuçları pek çok DTM'de Kuvarsın (kum) baskın minarel olduğunu ve bu minerali genellikle Feldispat (silt) ve İllit'in (kil) takip ettiğini göstermiştir. DTM yapıları içinde bulunan $\mathrm{Fe}_{2} \mathrm{O}_{3}$ (Hematit), $\mathrm{MgFe}_{2} \mathrm{O}_{4}$ (Magnesioferrit), $\mathrm{Mg}_{2} \mathrm{SiO}_{4}$ (Forsterit), $\mathrm{MgSiO}_{3}$ (Enstatit), $\mathrm{Fe}_{3} \mathrm{O}_{4}$ (Magnetit) ve $\mathrm{MgS}$ (Niningerit) mineralleri AYY-EK3B'ye göre H4-tahriş edici (Xi) özellikte olup R36/37/38 (Gözleri, solunum sistemini ve cildi tahriş edici) risk koduna sahiptirler. R36/37/38 için AYY-EK3B eşik konsantrasyonu \%20 olup, söz konusu minerallerin limit değerleri aşmadiğ 1 görülmüştür [54, 57]. DTM'lerin inorganik içerik açısından tehlikesiz özellik gösterdiği tespit edilmiştir. Kuvars için R48/20 (Zararlı: Uzun süreli solunması halinde sağlığa ciddi hasar tehlikesi) ve Kalsit için R37/38-41 (Solunum sistemini ve cildi tahriş edici, gözde ciddi hasar riski) risk kodları sebebiyle, DTM ile çalışırken toz maskesi/koruyucu gözlük ve eldiven kullanılmalıdır. Fiziko-kimyasal, mineralojik ve toksikolojik karakterizasyon sonuçları 1şığında, Türkiye'deki ticari limanlar ve balıkçı barınaklarından alınan DTM'lerin AYY EK3B'ye göre “tehlikesiz atık” ve atık kodunun 170506 (17 0505 dışındaki dip tarama çamuru) olduğu sonucuna varılmıştır. Önemli bir kontaminasyon sonucu remediasyon amaciyla yapilan taramalar haricinde, rutin tarama faaliyetlerinden kaynaklanan DTM'lerin genellikle Avrupa Atık Listesi (2000/532/EC)'ndeki kriterlere göre "tehlikesiz atık" olduğu belirtilmiştir [58, 59].

\subsection{DTM'lerin Sizma Potansiyelleri \\ (Leaching Potentials of DTMs)}

DTM'lere ait eluat (özütleme) çözeltisi ve orijinal DTM numunelerinin analizi neticesinde elde edilen değerler, "ADDDY-EK 2: Atıkların düzenli depolanabilmesi için kabul kriterleri"nde verilen limit değerler ile karşılaştırılarak Tablo 7 ve Tablo 8'de verilmiştir [60]. DTM'lerin TS EN 12457-4:2004 sızma testi sonuçlarına göre, eluatta $\mathrm{Cl}^{-}, \mathrm{F}^{-}, \mathrm{SO}_{4}^{-2}, \mathrm{TÇKM}, \mathrm{Mo}$ ve $\mathrm{Sb}$ konsantrasyonlarının, "ADDDY-EK 2" kriterleri tablosunda, 2-B) Tehlikesiz Atıkların Düzenli Depolanabilmesi Kriteri (II. Sınıf) sınır değerlerine uygun olduğu saptanmıştır. Denizel çevreden çıkarılan yüksek iletkenliğe sahip DTM'lerde gözlenen yüksek $\mathrm{Cl}^{-}$ve TÇKM içerikleri uygun karşılanmaktadır [61]. DTM'lerin düşük organik içerikleri sebebiyle olası organo-klorlu bileşik oluşum olasılığı oldukça düşüktür. $\mathrm{F}^{-}$kimyasal olarak inaktif olup, deponi sahaları için DTM kirleticisi değildir [62]. Deniz suyunda $\mathrm{Cl}^{-6}$ den sonraki en yoğun iyon olmasından ötürü DTM'lerde yüksek $\mathrm{SO}_{4}{ }^{-2}$ konsantrasyonu beklenebilir.

\subsection{DTM'lerin Faydalı Kullanım Alternatiflerinin Ön Değerlendirmesi \\ (Preevaluation of Beneficial Use Alternatives of DTMs)}

DTM'ler, ince kum, silt-kil, besin elementleri ve az da olsa organik madde içermeleri sebebiyle iyileştirilmiş yüzey toprağı olarak kentsel peyzaj uygulamalarında kullanılabilir; ancak, tuz giderimi, susuzlaştırma, eleme, organik iyileştirme, $\mathrm{pH}$ ayarı gibi işlemlerden geçirilmeleri gerekmektedir [63, 64]. Gerek beton gerekse karayolu dolgu malzemesi uygulamalarında kullanılan agregaların silt-kil fraksiyonu, Klorür ve Sülfat içerikleri de önemli olup [65, 66], beton basınç dayanımında ve yol taşıma gücünde zayıflama, donatı korozyonu, genleşme, yer altı sularına kontaminasyon vb. fiziksel, mekaniksel ve çevresel etkilere sebep olabilmektedir [67, 68]. Bu nedenle, DTM'lerin ince agrega olarak betonda ve karayolu dolgularında faydalı kullanımı için de çeşitli ön işlemler gerekmektedir.

Tablo 3. DTM'lerin tane boyu dağılımları (Grain size distributions of DTMs)

\begin{tabular}{llllll}
\hline \multirow{2}{*}{ Örnek No } & \multicolumn{5}{l}{ Tane boyutu (dağılım) (\%ăg.) } \\
\cline { 2 - 6 } & $\begin{array}{l}\text { Çak1 } \\
(>2 \mathrm{~mm})\end{array}$ & $\begin{array}{l}\text { Kaba Kum } \\
(2 \mathrm{~mm}-200 \mu \mathrm{m})\end{array}$ & $\begin{array}{l}\text { İnce Kum } \\
(200 \mu \mathrm{m}-63 \mu \mathrm{m})\end{array}$ & $\begin{array}{l}\text { Silt } \\
(63 \mu \mathrm{m}-2 \mu \mathrm{m})\end{array}$ & $\begin{array}{l}\text { Kil } \\
(<2 \mu \mathrm{m})\end{array}$ \\
\hline DTM-1 & $0,95 \pm 0,03$ & $26,81 \pm 0,41$ & $34,93 \pm 0,55$ & $18,68 \pm 0,29$ & $18,63 \pm 0,29$ \\
DTM-2 & $10,56 \pm 0,16$ & $11,90 \pm 0,18$ & $45,94 \pm 0,72$ & $5,27 \pm 0,08$ & $26,33 \pm 0,41$ \\
DTM-3 & $0,53 \pm 0,01$ & $13,04 \pm 0,20$ & $61,23 \pm 0,96$ & $21,61 \pm 0,33$ & $3,59 \pm 0,06$ \\
DTM-4 & $1,01 \pm 0,02$ & $36,82 \pm 0,58$ & $60,06 \pm 0,94$ & $1,69 \pm 0,03$ & $0,42 \pm 0,01$ \\
DTM-5 & $40,36 \pm 0,63$ & $36,86 \pm 0,58$ & $10,13 \pm 0,16$ & $6,81 \pm 0,10$ & $5,84 \pm 0,09$ \\
DTM-6 & $19,77 \pm 0,29$ & $17,69 \pm 0,27$ & $37,19 \pm 0,58$ & $22,26 \pm 0,34$ & $3,09 \pm 0,05$ \\
DTM-7 & $0,74 \pm 0,02$ & $39,60 \pm 0,59$ & $58,20 \pm 0,91$ & $1,36 \pm 0,03$ & $0,10 \pm 0,01$ \\
\hline
\end{tabular}


Tablo 4. DTM-1, DTM-2, DTM-3 ve DTM-4 kodlu numunelerin ağır metal analiz sonuçları (Heavy metal analysis results of DTM-1, DTM-2, DTM-3 and DTM-4 coded samples)

\begin{tabular}{|c|c|c|c|c|c|c|}
\hline $\begin{array}{l}\text { Ağır Metal (\%, } \\
\mathrm{mg} / \mathrm{kg})\end{array}$ & DTM-1 & DTM-2 & DTM-3 & DTM-4 & $\begin{array}{l}\text { Tehlike Sınıfı, Risk } \\
\text { Kodları ve Tehlikeler }\end{array}$ & $\begin{array}{l}\text { AYY } \\
\text { EK3B } \\
\text { Tehlikeli } \\
\text { Atık Eşik } \\
\text { Kons. }\end{array}$ \\
\hline Kurşun (Pb) & $\begin{array}{l}\% 1,2 * 10^{-3} \\
11,8 \pm 0,7 \\
\mathrm{mg} / \mathrm{kg}\end{array}$ & $\begin{array}{l}\% 0,0035 \\
35,4 \pm 2,1 \\
\mathrm{mg} / \mathrm{kg}\end{array}$ & $\begin{array}{l}\% 0,0011 \\
11,0 \pm 0,6 \\
\mathrm{mg} / \mathrm{kg}\end{array}$ & $\begin{array}{l}\% 0,0006 \\
6,0 \pm 0,3 \\
\mathrm{mg} / \mathrm{kg}\end{array}$ & $\begin{array}{l}(-): \text { R33 (-) } \\
\text { Üre. Kat1,2: R61 (H10) } \\
\text { Üre. Kat3: R62 (H10) } \\
\text { Xn: R20/22 (H5) } \\
\text { T+: R26/27/28 (H6) } \\
\text { N: R50/53 (H14) }\end{array}$ & $\begin{array}{l}- \\
\% 0,5 \\
\% 5 \\
\% 25 \\
\% 0,1 \\
\% 0,25\end{array}$ \\
\hline $\begin{array}{l}\text { Kadmiyum } \\
\text { (Cd) }\end{array}$ & $\begin{array}{l}<\% 1,0 * 10^{-5} \\
<0,1 \mathrm{mg} / \mathrm{kg}\end{array}$ & $\begin{array}{l}\% 0,00002 \\
0,17 \pm 0,01 \\
\mathrm{mg} / \mathrm{kg}\end{array}$ & $\begin{array}{l}<\% 0,00001 \\
<0,1 \mathrm{mg} / \mathrm{kg}\end{array}$ & $\begin{array}{l}<\% 0,00001 \\
<0,1 \mathrm{mg} / \mathrm{kg}\end{array}$ & $\begin{array}{l}\text { T+: R26 (H6) } \\
\text { Kans. Kat1,2: R45 (H7) } \\
\text { Üre. Kat3: R62, R63 } \\
\text { (H10) } \\
\text { Muta. Kat3: R68 (H11) } \\
\text { Xn, T: R48/23/25 (-) } \\
\text { N: R50/53 (H14) }\end{array}$ & $\begin{array}{l}\% 0,1 \\
\% 0,1 \\
\% 5 \\
\% 1 \\
\% 3 \\
\% 0,25\end{array}$ \\
\hline $\operatorname{Krom}(\mathrm{Cr})$ & $\begin{array}{l}\% 0,0085 \\
85 \pm 3 \mathrm{mg} / \mathrm{kg}\end{array}$ & $\begin{array}{l}\% 0,0111 \\
111 \pm 4 \\
\mathrm{mg} / \mathrm{kg}\end{array}$ & $\begin{array}{l}\% 0,0047 \\
47 \pm 2 \mathrm{mg} / \mathrm{kg}\end{array}$ & $\begin{array}{l}\% 0,0094 \\
94 \pm 4 \mathrm{mg} / \mathrm{kg}\end{array}$ & $\begin{array}{l}\text { F: R11 (H3A) } \\
\text { Kans. Kat3: R40 (H7) } \\
\text { N: R52 (H14) }\end{array}$ & $\begin{array}{l}- \\
\% 1 \\
\% 25\end{array}$ \\
\hline Bakır $(\mathrm{Cu})$ & $\begin{array}{l}\% 0,0015 \\
15 \pm 1 \mathrm{mg} / \mathrm{kg}\end{array}$ & $\begin{array}{l}\% 0,0046 \\
46 \pm 4 \mathrm{mg} / \mathrm{kg}\end{array}$ & $\begin{array}{l}\% 0,0024 \\
24 \pm 2 \mathrm{mg} / \mathrm{kg}\end{array}$ & $\begin{array}{l}\% 0,0012 \\
12 \pm 1 \mathrm{mg} / \mathrm{kg}\end{array}$ & $\begin{array}{l}\text { F: R11 (H3A) } \\
\text { N: R52 (H14) } \\
\text { Xi: R36/37/38 (H4) }\end{array}$ & $\begin{array}{l}- \\
\% 25 \\
\% 20\end{array}$ \\
\hline Nikel (Ni) & $\begin{array}{l}\% 0,004 \\
40 \pm 2 \mathrm{mg} / \mathrm{kg}\end{array}$ & $\begin{array}{l}\% 0,006 \\
60 \pm 4 \mathrm{mg} / \mathrm{kg}\end{array}$ & $\begin{array}{l}\% 0,003 \\
30 \pm 2 \mathrm{mg} / \mathrm{kg}\end{array}$ & $\begin{array}{l}\% 0,0035 \\
35 \pm 2 \mathrm{mg} / \mathrm{kg}\end{array}$ & $\begin{array}{l}\text { Kans. Kat3: R40 (H7) } \\
\text { Xi: R43 (H13) } \\
\text { Xn, T: R48/23 (-) } \\
\text { N: R52/53 (H14) }\end{array}$ & $\begin{array}{l}\% 1 \\
\% 1 \\
\% 3 \\
\% 25\end{array}$ \\
\hline Çinko (Zn) & $\begin{array}{l}\% 0,0042 \\
42 \pm 2 \mathrm{mg} / \mathrm{kg}\end{array}$ & $\begin{array}{l}\% 0,008 \\
80 \pm 4 \mathrm{mg} / \mathrm{kg}\end{array}$ & $\begin{array}{l}\% 0,005 \\
50 \pm 2 \mathrm{mg} / \mathrm{kg}\end{array}$ & $\begin{array}{l}\% 0,004 \\
40 \pm 2 \mathrm{mg} / \mathrm{kg}\end{array}$ & $\begin{array}{l}\text { F: R15, R17 (H3A) } \\
\text { N: R50/53 (H14) }\end{array}$ & $\begin{array}{l}\% 0,3 \\
\% 0,25\end{array}$ \\
\hline Civa (Hg) & $\begin{array}{l}\% 0,000003 \\
0,030 \pm 0,005 \\
\mathrm{mg} / \mathrm{kg}\end{array}$ & $\begin{array}{l}\% 9^{*} 10^{-6} \\
0,090 \pm 0,01 \\
3 \mathrm{mg} / \mathrm{kg}\end{array}$ & $\begin{array}{l}\% 0,000005 \\
0,052 \pm 0,00 \\
8 \mathrm{mg} / \mathrm{kg}\end{array}$ & $\begin{array}{l}0,000018 \\
0,180 \pm 0,02 \\
7 \mathrm{mg} / \mathrm{kg}\end{array}$ & $\begin{array}{l}\text { T+: R26 (H6) } \\
\text { Üre. Kat1,2: R61 (H10) } \\
\text { Xn, T: R48/23 (-) } \\
\text { N: R50/53 (H14) }\end{array}$ & $\begin{array}{l}\% 0,1 \\
\% 0,5 \\
\% 3 \\
\% 0,25\end{array}$ \\
\hline Arsenik (As) & $\begin{array}{l}\% 0,0008 \\
8,04 \pm 0,68 \\
\mathrm{mg} / \mathrm{kg}\end{array}$ & $\begin{array}{l}\% 0,0013 \\
13,00 \pm 1,11 \\
\mathrm{mg} / \mathrm{kg}\end{array}$ & $\begin{array}{l}\% 0,0017 \\
17,20 \pm 1,44 \\
\mathrm{mg} / \mathrm{kg}\end{array}$ & $\begin{array}{l}\% 0,002 \\
20,40 \pm 1,69 \\
\mathrm{mg} / \mathrm{kg}\end{array}$ & $\begin{array}{l}\mathrm{T}: \mathrm{R} 23 / 25(\mathrm{H} 6) \\
\mathrm{N}: \mathrm{R} 50 / 53(\mathrm{H} 14)\end{array}$ & $\begin{array}{l}\% 3 \\
\% 0,25\end{array}$ \\
\hline
\end{tabular}


Tablo 5. DTM-5, DTM-6 ve DTM-7 kodlu numunelerin ağır metal analiz sonuçları (Heavy metal analysis results of DTM-5, DTM-6 and DTM-7 coded samples)

\begin{tabular}{|c|c|c|c|c|c|}
\hline $\begin{array}{l}\text { Ağır Metal (\%, } \\
\mathrm{mg} / \mathrm{kg})\end{array}$ & DTM-5 & DTM-6 & DTM-7 & $\begin{array}{l}\text { Tehlike Sınıf, Risk } \\
\text { Kodları ve Tehlikeler }\end{array}$ & $\begin{array}{l}\text { AYY EK3B } \\
\text { Tehlikeli Atık } \\
\text { Eşik Kons. }\end{array}$ \\
\hline Kurşun (Pb) & $\begin{array}{l}\% 0,0013 \\
13,0 \pm 0,8 \\
\mathrm{mg} / \mathrm{kg}\end{array}$ & $\begin{array}{l}\% 0,0042 \\
42,3 \pm 2,5 \\
\mathrm{mg} / \mathrm{kg}\end{array}$ & $\begin{array}{l}\% 0,0006 \\
6,0 \pm 0,3 \\
\mathrm{mg} / \mathrm{kg}\end{array}$ & $\begin{array}{l}\text { (-): R33 (-) } \\
\text { Üre. Kat1,2: R61 (H10) } \\
\text { Üre. Kat3: R62 (H10) } \\
\text { Xn: R20/22 (H5) } \\
\text { T+: R26/27/28 (H6) } \\
\text { N: R50/53 (H14) }\end{array}$ & $\begin{array}{l}- \\
\% 0,5 \\
\% 5 \\
\% 25 \\
\% 0,1 \\
\% 0,25\end{array}$ \\
\hline $\begin{array}{l}\text { Kadmiyum } \\
\text { (Cd) }\end{array}$ & $\begin{array}{l}<\% 0,00004 \\
0,43 \pm 0,03 \\
\mathrm{mg} / \mathrm{kg}\end{array}$ & $\begin{array}{l}\% 0,00004 \\
0,40 \pm 0,03 \\
\mathrm{mg} / \mathrm{kg}\end{array}$ & $\begin{array}{l}\% 0,00001 \\
0,11 \pm 0,01 \\
\mathrm{mg} / \mathrm{kg}\end{array}$ & $\begin{array}{l}\text { T+: R26 (H6) } \\
\text { Kans. Kat1,2: R45 (H7) } \\
\text { Üre. Kat3: R62, R63 (H10) } \\
\text { Muta. Kat3: R68 (H11) } \\
\text { Xn, T: R48/23/25 (-) } \\
\text { N: R50/53 (H14) }\end{array}$ & $\begin{array}{l}\% 0,1 \\
\% 0,1 \\
\% 5 \\
\% 1 \\
\% 3 \\
\% 0,25\end{array}$ \\
\hline Krom (Cr) & $\begin{array}{l}\% 0,014 \\
140 \pm 5 \mathrm{mg} / \mathrm{kg}\end{array}$ & $\begin{array}{l}\% 0,004 \\
40 \pm 1 \mathrm{mg} / \mathrm{kg}\end{array}$ & $\begin{array}{l}\% 0,09 \\
900 \pm 32 \\
\mathrm{mg} / \mathrm{kg}\end{array}$ & $\begin{array}{l}\text { F: R11 (H3A) } \\
\text { Kans. Kat3: R40 (H7) } \\
\text { N: R52 (H14) }\end{array}$ & $\begin{array}{l}- \\
\% 1 \\
\% 25\end{array}$ \\
\hline Bakır $(\mathrm{Cu})$ & $\begin{array}{l}\% 0,0023 \\
23 \pm 2 \mathrm{mg} / \mathrm{kg}\end{array}$ & $\begin{array}{l}\% 0,0031 \\
31 \pm 3 \mathrm{mg} / \mathrm{kg}\end{array}$ & $\begin{array}{l}\% 0,00174 \\
17 \pm 1 \\
\mathrm{mg} / \mathrm{kg}\end{array}$ & $\begin{array}{l}\text { F: R11 (H3A) } \\
\text { N: R52 (H14) } \\
\text { Xi: R36/37/38 (H4) }\end{array}$ & $\begin{array}{l}- \\
\% 25 \\
\% 20\end{array}$ \\
\hline Nikel (Ni) & $\begin{array}{l}\% 0,0132 \\
132 \pm 7 \mathrm{mg} / \mathrm{kg}\end{array}$ & $\begin{array}{l}\% 0,0031 \\
31 \pm 2 \mathrm{mg} / \mathrm{kg}\end{array}$ & $\begin{array}{l}\% 0,069 \\
690 \pm 37 \\
\mathrm{mg} / \mathrm{kg}\end{array}$ & $\begin{array}{l}\text { Kans. Kat3: R40 (H7) } \\
\text { Xi: R43 (H13) } \\
\text { Xn, T: R48/23 (-) } \\
\text { N: R52/53 (H14) }\end{array}$ & $\begin{array}{l}\% 1 \\
\% 1 \\
\% 3 \\
\% 25\end{array}$ \\
\hline Çinko (Zn) & $\begin{array}{l}\% 0,013 \\
130 \pm 6 \mathrm{mg} / \mathrm{kg}\end{array}$ & $\begin{array}{l}\% 0,0079 \\
79 \pm 4 \mathrm{mg} / \mathrm{kg}\end{array}$ & $\begin{array}{l}\% 0,0035 \\
35 \pm 2 \\
\mathrm{mg} / \mathrm{kg}\end{array}$ & $\begin{array}{l}\text { F: R15, R17 (H3A) } \\
\text { N: R50/53 (H14) }\end{array}$ & $\begin{array}{l}\% 0,3 \\
\% 0,25\end{array}$ \\
\hline Civa (Hg) & $\begin{array}{l}\% 0,0002 \\
2,001 \pm 0,289 \\
\mathrm{mg} / \mathrm{kg}\end{array}$ & $\begin{array}{l}\% 0,000014 \\
0,144 \pm 0,021 \\
\mathrm{mg} / \mathrm{kg}\end{array}$ & $\begin{array}{l}<\% 0,000 \\
001 \\
<0,01 \\
\mathrm{mg} / \mathrm{kg}\end{array}$ & $\begin{array}{l}\text { T+: R26 (H6) } \\
\text { Üre. Kat1,2: R61 (H10) } \\
\text { Xn, T: R48/23 (-) } \\
\text { N: R50/53 (H14) }\end{array}$ & $\begin{array}{l}\% 0,1 \\
\% 0,5 \\
\% 3 \\
\% 0,25\end{array}$ \\
\hline Arsenik (As) & $\begin{array}{l}\% 0,035 \\
350,00 \pm 28,90 \\
\mathrm{mg} / \mathrm{kg}\end{array}$ & $\begin{array}{l}\% 0,00086 \\
8,61 \pm 0,69 \\
\mathrm{mg} / \mathrm{kg}\end{array}$ & $\begin{array}{l}\% 0,00084 \\
8,40 \pm 0,69 \\
\mathrm{mg} / \mathrm{kg}\end{array}$ & $\begin{array}{l}\mathrm{T}: \mathrm{R} 23 / 25(\mathrm{H} 6) \\
\mathrm{N}: \mathrm{R} 50 / 53(\mathrm{H} 14)\end{array}$ & $\begin{array}{l}\% 3 \\
\% 0,25\end{array}$ \\
\hline
\end{tabular}


Başar ve ark. / Journal of the Faculty of Engineering and Architecture of Gazi University 32:4 (2017) 1063-1076

Tablo 6. DTM'lerin mineralojik bileşimleri (Mineralogical compositions of DTMs)

\begin{tabular}{|c|c|c|c|c|c|c|c|c|c|}
\hline \multirow{2}{*}{ Mineral } & \multicolumn{7}{|l|}{ \%ağ. } & \multirow{2}{*}{$\begin{array}{l}\text { Tehlike Sinıfı, } \\
\text { Risk Kodları } \\
\text { ve Tehlikeler }\end{array}$} & \multirow{2}{*}{$\begin{array}{l}\text { AYY } \\
\text { EK3B } \\
\text { Tehlikeli } \\
\text { Atık eşik } \\
\text { kons. } \\
\end{array}$} \\
\hline & $\begin{array}{l}\text { DTM } \\
-1 \\
\end{array}$ & $\begin{array}{l}\text { DTM } \\
-2 \\
\end{array}$ & $\begin{array}{l}\text { DTM } \\
-3 \\
\end{array}$ & $\begin{array}{l}\text { DTM } \\
-4 \\
\end{array}$ & $\begin{array}{l}\text { DTM } \\
-5 \\
\end{array}$ & $\begin{array}{l}\text { DTM } \\
-6 \\
\end{array}$ & $\begin{array}{l}\text { DTM } \\
-7 \\
\end{array}$ & & \\
\hline Kuvars, $\mathrm{SiO}_{2}$ & 28,9 & 17,1 & 18,3 & 43,0 & 8,6 & 31,3 & 11,1 & $\begin{array}{l}\text { Xn, T: R48/20 } \\
(-)\end{array}$ & $25 \%$ \\
\hline Feldispat & 18,2 & 17,1 & 11,5 & 6,9 & 43,4 & 6,9 & 7,8 & - & - \\
\hline $\begin{array}{l}\text { Illit, } \\
(\mathrm{K}, \mathrm{H} 3 \mathrm{O}) \mathrm{A} 12 \mathrm{Si} 3 \\
\mathrm{AlO} 10(\mathrm{OH}) 2\end{array}$ & 12,0 & 9,3 & 11,7 & 7,6 & 9,1 & 12,0 & 3,2 & - & - \\
\hline Kalsit, $\mathrm{CaCO} 3$ & 9,8 & 6,6 & 8,5 & 2,9 & 0,6 & 3,6 & 30,6 & $\begin{array}{l}\text { Xi: R41 (H4) } \\
\text { Xi: R37/38 } \\
\text { (H4) }\end{array}$ & $\begin{array}{l}10 \% \\
20 \%\end{array}$ \\
\hline $\begin{array}{l}\text { Almandin, } \\
\text { Fe3Al2(SiO4)3 }\end{array}$ & ND & 2,9 & 2,3 & ND & ND & ND & ND & - & - \\
\hline Anhidrit, CaSO4 & ND & 0,7 & 1,3 & 2,5 & 1,9 & 3,0 & ND & $\begin{array}{l}\mathrm{Xi}: \mathrm{R} 36 / 37 \\
\text { (H4) }\end{array}$ & $20 \%$ \\
\hline Hematit, Fe2O3 & 1,5 & 0,6 & 0,7 & 0,5 & 0,9 & 3,9 & 3,1 & $\begin{array}{l}\text { Xi: R36/37/38 } \\
\text { (H4) }\end{array}$ & $20 \%$ \\
\hline $\begin{array}{l}\text { Potasyum Magn. } \\
\mathrm{Cl}, \mathrm{KMgCl} 3\end{array}$ & 1,1 & ND & ND & ND & ND & ND & ND & - & - \\
\hline $\begin{array}{l}\text { Magnesioferrit, } \\
\mathrm{MgFe} 2 \mathrm{O} 4\end{array}$ & ND & 2,4 & 2,4 & 2,2 & 2,8 & ND & ND & $\begin{array}{l}\text { Xi: R36/37/38 } \\
\text { (H4) }\end{array}$ & $20 \%$ \\
\hline $\begin{array}{l}\text { Forsterit, } \\
\mathrm{Mg} 2 \mathrm{SiO} 4\end{array}$ & ND & ND & ND & ND & ND & ND & 1,3 & $\begin{array}{l}\text { Xn: R20 (H5) } \\
\text { Xi: R36/37/38 }\end{array}$ & $\begin{array}{l}25 \% \\
20 \%\end{array}$ \\
\hline Enstatit, MgSiO3 & ND & ND & ND & ND & 1,9 & ND & $\mathrm{ND}$ & (H4) & \\
\hline $\begin{array}{l}\text { Potasyum Klorat, } \\
\mathrm{K}(\mathrm{ClO} 4)\end{array}$ & ND & ND & ND & ND & 0,7 & ND & ND & $\begin{array}{l}\text { O: R9 (H2) } \\
\text { Xn: R20/22 } \\
\text { (H5) } \\
\text { N: R51/53 } \\
\text { (H14) }\end{array}$ & $\begin{array}{l}- \\
25 \% \\
2,5 \%\end{array}$ \\
\hline Magnetit, Fe3O4 & ND & ND & ND & 2,5 & ND & ND & ND & $\begin{array}{l}\text { (-): R66 (-) } \\
\text { Xi: R36/37/38 } \\
\text { (H4) }\end{array}$ & $20 \%$ \\
\hline $\begin{array}{l}\text { Diopsid, } \\
\mathrm{CaMg}(\mathrm{SiO} 3) 2\end{array}$ & ND & ND & ND & ND & 1,1 & 5,4 & 3,1 & - & - \\
\hline Niningerit, MgS & ND & ND & ND & ND & ND & 1,8 & ND & $\begin{array}{l}\text { F: R15/29 } \\
\text { (H3A) } \\
\text { Xi: R36/37/38 } \\
\text { (H4) } \\
\text { N: R51 (H14) }\end{array}$ & $\begin{array}{l}- \\
20 \% \\
2,5\end{array}$ \\
\hline $\begin{array}{l}\text { Lizardit, } \\
\text { Mg3Si2O5(OH) } \\
4\end{array}$ & ND & ND & ND & ND & ND & ND & 6,7 & - & - \\
\hline
\end{tabular}


Tablo 7. DTM-1, DTM-2, DTM-3 ve DTM-4 kodlu numunelerin sıma potansiyelleri ve ADDDY-EK2 kalite kriterleri (Leaching potentials of DTM-1, DTM-2, DTM-3 and DTM-4 coded samples and ADDDY-Appendix2 quality criteria)

\begin{tabular}{|c|c|c|c|c|c|c|c|c|}
\hline Parametre & DTM-1 & DTM-2 & DTM-3 & DTM-4 & III.Sinif & II.Sinıf & I.Sinıf & Yöntem \\
\hline \multicolumn{9}{|c|}{ Eluat $(\mathrm{L} / \mathrm{S}=10 \mathrm{~L} / \mathrm{kg})$} \\
\hline As $(\mu \mathrm{g} / 1)$ & $12,7 \pm 1,2$ & $11,8 \pm 1,1$ & $13,2 \pm 1,2$ & $5,3 \pm 0,5$ & 50 & 200 & 2,500 & \multirow{5}{*}{$\begin{array}{l}\text { EPA } \\
6020 A\end{array}$} \\
\hline $\mathrm{Ba}(\mu \mathrm{g} / 1)$ & $46,7 \pm 4,0$ & $50,5 \pm 4,3$ & $30,7 \pm 2,6$ & $30,2 \pm 2,6$ & 2.000 & 10.000 & 30.000 & \\
\hline $\mathrm{Cd}(\mu \mathrm{g} / 1)$ & $<0,01$ & $0,10 \pm 0,01$ & $0,12 \pm 0,01$ & $0,2 \pm 0,03$ & 4 & 100 & 500 & \\
\hline $\mathrm{Cr}(\mu \mathrm{g} / 1)$ & $<1,00$ & $8,82 \pm 0,54$ & $6,06 \pm 0,37$ & $0,77 \pm 0,05$ & 50 & 1.000 & 7.000 & \\
\hline $\mathrm{Cu}(\mu \mathrm{g} / 1)$ & $8,4 \pm 0,7$ & $31,1 \pm 2,7$ & $35,5 \pm 3,1$ & $16,0 \pm 1,4$ & 200 & 5.000 & 10.000 & \\
\hline $\mathrm{Hg}(\mu \mathrm{g} / \mathrm{l})$ & $<0,13$ & $<0,13$ & $<0,13$ & $<0,13$ & 1 & 20 & 200 & \multirow[t]{2}{*}{ SM-3112 } \\
\hline $\operatorname{Mo}(\mu \mathrm{g} / \mathrm{l})$ & $5,9 \pm 0,3$ & $20,2 \pm 1,2$ & $10,5 \pm 0,6$ & $103,0 \pm 5,9$ & 50 & 1.000 & 3.000 & \\
\hline $\mathrm{Ni}(\mu \mathrm{g} / \mathrm{l})$ & $1,67 \pm 0,20$ & $11,60 \pm 1,4$ & $7,94 \pm 0,93$ & $7,73 \pm 0,91$ & 40 & 1.000 & 4.000 & \multirow{5}{*}{$\begin{array}{l}\text { EPA } \\
6020 A\end{array}$} \\
\hline $\mathrm{Pb}(\mu \mathrm{g} / \mathrm{l})$ & $1,07 \pm 0,19$ & $\begin{array}{l}17,00 \pm 3,0 \\
9\end{array}$ & $9,84 \pm 1,79$ & $1,70 \pm 0,31$ & 50 & 1.000 & 5.000 & \\
\hline $\mathrm{Sb}(\mu \mathrm{g} / 1)$ & $2,45 \pm 0,59$ & $6,11 \pm 1,47$ & $2,49 \pm 0,60$ & $6,90 \pm 1,66$ & 6 & 70 & 500 & \\
\hline $\mathrm{Se}(\mu \mathrm{g} / 1)$ & $2,7 \pm 0,6$ & $<1,0$ & $<1,0$ & $<1,0$ & 10 & 50 & 700 & \\
\hline $\mathrm{Zn}(\mu \mathrm{g} / \mathrm{l})$ & $<5,0$ & $41,9 \pm 2,4$ & $29,9 \pm 1,7$ & $20,0 \pm 1,1$ & 400 & 5.000 & 20.000 & \\
\hline $\mathrm{Cl}^{-}(\mathrm{mg} / \mathrm{l})$ & $601 \pm 33$ & $705 \pm 39$ & $456 \pm 25$ & $1.103 \pm 61$ & 80 & 1.500 & 2.500 & \multirow{3}{*}{ SM-4110B } \\
\hline $\mathrm{F}^{-}(\mathrm{mg} / \mathrm{l})$ & $0,20 \pm 0,01$ & $0,34 \pm 0,02$ & $0,31 \pm 0,02$ & $2,60 \pm 0,13$ & 1 & 15 & 50 & \\
\hline $\mathrm{SO}_{4}^{-2}(\mathrm{mg} / \mathrm{l})$ & $102,9 \pm 1,1$ & $94,7 \pm 1,0$ & $64,3 \pm 0,7$ & $164,0 \pm 1,8$ & 100 & 2.000 & 5.000 & \\
\hline ÇOK (mg/l) & $<0,5$ & $4,1 \pm 0,3$ & $1,8 \pm 0,1$ & $<0,5$ & 50 & 80 & 100 & SM-5310B \\
\hline $\begin{array}{l}\text { TÇKM } \\
(\mathrm{mg} / \mathrm{l})\end{array}$ & $1.204 \pm 23$ & $1.559 \pm 30$ & $1.120 \pm 21$ & $2.388 \pm 46$ & 400 & 6.000 & 10.000 & SM-2540C \\
\hline Fenol (mg/l) & $<0,07$ & $<0,07$ & $<0,07$ & $<0,07$ & 0,1 & - & - & SM-5530D \\
\hline \multicolumn{9}{|l|}{ Orijinal Katı } \\
\hline $\begin{array}{l}\text { TOK } \\
(\mathrm{mg} / \mathrm{kg})\end{array}$ & $<1.884$ & 9.078 & 5.960 & $<1.884$ & 30.000 & 50.000 & 60.000 & SM-5310B \\
\hline $\begin{array}{l}\text { BTEX } \\
(\mathrm{mg} / \mathrm{kg})\end{array}$ & $<0,5$ & $<0,5$ & $<0,5$ & $<0,5$ & 6 & - & - & $\begin{array}{l}\text { EPA } \\
8015 C\end{array}$ \\
\hline $\begin{array}{l}\text { PCB } \\
(\mathrm{mg} / \mathrm{kg})\end{array}$ & $<0,1$ & $<0,1$ & $<0,1$ & $<0,1$ & 1 & - & - & ISO 10382 \\
\hline $\begin{array}{l}\text { Hidrokarbon } \\
(\mathrm{mg} / \mathrm{kg})\end{array}$ & 79 & 162 & $<65$ & 82 & 500 & - & - & $\begin{array}{l}\text { BS EN } \\
14039\end{array}$ \\
\hline $\begin{array}{l}\text { Yanma } \\
\text { kayb1 (\%) }\end{array}$ & $<2,3$ & 4,2 & 3,4 & $<2,3$ & - & - & $\% 10$ & $\begin{array}{l}\text { TS EN } \\
12879 \\
\end{array}$ \\
\hline
\end{tabular}


Tablo 8. DTM-5, DTM-6 ve DTM-7 kodlu numunelerin sızma potansiyelleri ve ADDDY-EK2 kalite kriterleri (Leaching potentials of DTM-5, DTM-6 and DTM-7 coded samples and ADDDY-Appendix2 quality criteria)

\begin{tabular}{|c|c|c|c|c|c|c|c|}
\hline Parametre & DTM-5 & DTM-6 & DTM-7 & III. Sinıf & II. Sinif & I.Sinif & Yöntem \\
\hline \multicolumn{8}{|c|}{ Eluat $(\mathrm{L} / \mathrm{S}=10 \mathrm{~L} / \mathrm{kg})$} \\
\hline As $(\mu \mathrm{g} / 1)$ & $28,7 \pm 2,6$ & $5,0 \pm 0,5$ & $2,7 \pm 0,2$ & 50 & 200 & 2,500 & \multirow{5}{*}{ EPA 6020A } \\
\hline $\mathrm{Ba}(\mu \mathrm{g} / \mathrm{l})$ & $50,8 \pm 4,3$ & $75,9 \pm 6,5$ & $18,0 \pm 1,5$ & 2.000 & 10.000 & 30.000 & \\
\hline $\mathrm{Cd}(\mu \mathrm{g} / 1)$ & $<0,01$ & $0,31 \pm 0,03$ & $0,1 \pm 0,01$ & 4 & 100 & 500 & \\
\hline $\mathrm{Cr}(\mu \mathrm{g} / 1)$ & $0,96 \pm 0,06$ & $1,35 \pm 0,08$ & $0,26 \pm 0,02$ & 50 & 1.000 & 7.000 & \\
\hline $\mathrm{Cu}(\mu \mathrm{g} / 1)$ & $14,9 \pm 1,3$ & $9,9 \pm 0,9$ & $7,7 \pm 0,7$ & 200 & 5.000 & 10.000 & \\
\hline $\mathrm{Hg}(\mu \mathrm{g} / 1)$ & $<0,13$ & $<0,13$ & $<0,13$ & 1 & 20 & 200 & \multirow[t]{2}{*}{ SM-3112 } \\
\hline Mo $(\mu \mathrm{g} / 1)$ & $37,4 \pm 2,1$ & $135,0 \pm 0,08$ & $7,0 \pm 0,4$ & 50 & 1.000 & 3.000 & \\
\hline $\mathrm{Ni}(\mu \mathrm{g} / \mathrm{l})$ & $8,20 \pm 0,96$ & $3,47 \pm 0,41$ & $5,02 \pm 0,59$ & 40 & 1.000 & 4.000 & \multirow{5}{*}{ EPA 6020A } \\
\hline $\mathrm{Pb}(\mu \mathrm{g} / 1)$ & $1,20 \pm 0,22$ & $3,15 \pm 0,57$ & $0,75 \pm 0,14$ & 50 & 1.000 & 5.000 & \\
\hline $\mathrm{Sb}(\mu \mathrm{g} / 1)$ & $2,93 \pm 0,70$ & $15,70 \pm 3,77$ & $0,75 \pm 0,18$ & 6 & 70 & 500 & \\
\hline $\mathrm{Se}(\mu \mathrm{g} / 1)$ & $1,1 \pm 0,2$ & $<1,0$ & $1,1 \pm 0,2$ & 10 & 50 & 700 & \\
\hline $\mathrm{Zn}(\mu \mathrm{g} / 1)$ & $15,5 \pm 0,9$ & $22,6 \pm 1,3$ & $7,0 \pm 0,4$ & 400 & 5.000 & 20.000 & \\
\hline Cl- (mg/l) & $950 \pm 52$ & $545 \pm 30$ & $1.000 \pm 55$ & 80 & 1.500 & 2.500 & \multirow{3}{*}{ SM-4110B } \\
\hline $\mathrm{F}-(\mathrm{mg} / \mathrm{l})$ & $0,67 \pm 0,03$ & $0,78 \pm 0,04$ & $0,97 \pm 0,05$ & 1 & 15 & 50 & \\
\hline $\mathrm{SO} 4-2(\mathrm{mg} / \mathrm{l})$ & $186,0 \pm 2,0$ & $41,9 \pm 0,4$ & $155,4 \pm 1,7$ & 100 & 2.000 & 5.000 & \\
\hline ÇOK (mg/l) & $2,1 \pm 0,1$ & $10,3 \pm 0,7$ & $1,5 \pm 0,1$ & 50 & 80 & 100 & SM-5310B \\
\hline TÇKM (mg/l) & $2.040 \pm 39$ & $1.212 \pm 23$ & $2.006 \pm 38$ & 400 & 6.000 & 10.000 & SM-2540C \\
\hline Fenol (mg/l) & $<0,07$ & $<0,07$ & $<0,07$ & 0,1 & - & - & SM-5530D \\
\hline \multicolumn{8}{|l|}{ Orijinal Katı } \\
\hline TOK (mg/kg) & 2.318 & 10.708 & $<1.884$ & 30.000 & 50.000 & 60.000 & SM-5310B \\
\hline BTEX (mg/kg) & $<0,5$ & $<0,5$ & $<0,5$ & 6 & - & - & EPA $8015 C$ \\
\hline PCB (mg/kg) & $<0,1$ & 0,2 & 0,5 & 1 & - & - & ISO 10382 \\
\hline $\begin{array}{l}\text { Hidrokarbon } \\
(\mathrm{mg} / \mathrm{kg})\end{array}$ & $<65$ & $<65$ & $<65$ & 500 & - & - & $\begin{array}{l}\text { BS EN } \\
14039\end{array}$ \\
\hline $\begin{array}{l}\text { Yanma kaybı } \\
(\%)\end{array}$ & 4,7 & 4,3 & 4,1 & - & - & $\% 10$ & $\begin{array}{l}\text { TS EN } \\
12879\end{array}$ \\
\hline
\end{tabular}

Bu bilgiler 1şı̆̆ında, Türkiye'deki yedi pilot bölgeden alınan DTM'lerin karakterizasyon sonuçları baz alınmış, söz konusu DTM'ler zirai/ürün uygulamalarındaki (iyileştirilmiş yüzey toprağı, beton, dolgu malzemesi) olası faydalı kullanımları ön değerlendirmeye tabii tutularak Tablo 9' da verilmiştir. Ön işlem uygulanması durumunda fizikokimyasal yapıları sebebiyle iyileştirilmiş yüzey toprağı olarak DTM-4, DTM-5, DTM-7'nin, betonda ince agrega olarak DTM-4 ve DTM-7'nin ve karayolu dolgusu olarak DTM-5 haricindeki tüm DTM'lerin umut vaad ettiği düşünülmüştür. Ancak, her bir uygulama için ön işlemler gerçekleştirilerek elde edilecek sonuçların ürün bazında teknik, çevresel ve ekonomik değerlendirmelerinin yapılması gerektiğinden, DİPTAR Projesi kapsamında söz konusu faydalı kullanımlar için geniş çaplı laboratuvar çalışmaları yürütülmüş olup, elde edilen bulgular devam yayınlarda verilecektir.
Tablo 9. DTM'lerin çeşitli faydalı kullanım alternatifleri için ön değerlendirmesi

(Preevaluation of DTMs for several beneficial use alternatives)

\begin{tabular}{llll}
\hline $\begin{array}{l}\text { Numune } \\
\text { Kodu }\end{array}$ & $\begin{array}{l}\text { İyileştirilmiş } \\
\text { Yüzey Toprağ1 }\end{array}$ & $\begin{array}{l}\text { Betonda } \\
\text { İnce } \\
\text { Agrega }\end{array}$ & $\begin{array}{l}\text { Karayolu } \\
\text { Dolgu } \\
\text { Malzemesi }\end{array}$ \\
\hline DTM-1 & - & - & + \\
DTM-2 & - & - & + \\
DTM-3 & - & - & + \\
DTM-4 & + & + & + \\
DTM-5 & + & - & - \\
DTM-6 & - & - & + \\
DTM-7 & + & + & + \\
\hline
\end{tabular}




\section{SIMGELER (SYMBOLS)}

\section{Klsaltmalar (Abbreviations)}

$\begin{array}{ll}\text { ADDDY } & \text { Atıkların Düzenli Depolanmasına } \\ & \text { Dair Yönetmelik } \\ \text { AYY } & \text { Atık Yönetimi Yönetmeliği } \\ \text { BTEX } & \text { Benzen, toluen, etil benzen, ksilen } \\ \text { CTP } & \text { Cam elyaf takviyeli polyester } \\ \text { ÇED } & \text { Çevresel etki değerlendirmesi } \\ \text { ÇOK } & \text { Çözünmüş organik karbon } \\ \text { DIPTAR } & \text { Deniz dip tarama uygulamaları ve tarama } \\ & \text { malzemesinin çevresel uygulamaları } \\ \text { DTM } & \text { Dip tarama malzemesi } \\ \text { GC-HRMS } & \text { Gaz kromatografi-yüksek çözünürlüklü } \\ & \text { kütle spektrometri } \\ \text { GC-MS } & \text { Gaz kromatografi-kütle spektrometri } \\ \text { HDPE } & \text { Yüksek yoğunluklu polietilen } \\ \text { ICP-OES } & \text { İndüktif eşlenmiş plazma-optik emisyon } \\ & \text { spektroskopi } \\ \text { LC-MSMS } & \text { Sivı kromatografi-kütle spektrometri-kütle } \\ & \text { spektrometri } \\ \text { MAM } & \text { Marmara Araştırma Merkezi } \\ \text { ND } & \text { Tespit edilemedi } \\ \text { PAH } & \text { Poliaromatik hidrokarbon } \\ \text { PCB } & \text { Poliklorlu bifenil } \\ \text { PCDD/F } & \text { Dioksin/furan } \\ \text { PVC } & \text { Polivinilkloür } \\ \text { TÇKM } & \text { Toplam çözünen katı madde } \\ \text { TEQ } & \text { Toksik eşdeğerlik } \\ \text { TOK } & \text { Toplam organik karbon } \\ \text { XRD } & \text { X-1şını difraktometresi } \\ & \end{array}$

\section{SONUÇLAR (CONCLUSIONS)}

Çalışma kapsamında elde edilen sonuçlar şu şekilde özetlenebilir: DTM örnekleri organik ve inorganik madde içerikleri bakımından tehlikesiz özellik göstermektedir. DTM'lerin denizel ortam bakterisi Vibrio fischeri [32] üzerinde ekotoksik etki göstermedikleri, tatlı su balığ 1 Lepistes Reticulates ve laboratuvar faresi BALB/c (erkek fare) için ise herhangi bir akut risk oluşturmadıkları ve balık/fare ölümüne sebebiyet vermedikleri belirlenmiştir; ancak, olası kronik etkiler bu çalışma kapsamında ele alınmamıştır. DTM'ler esas olarak ince ve kaba kum içermekte olup kum kaynaklı malzemeler olarak düşünülebilir. DTM'lerin AYY-EK3B'ye göre “tehlikesiz atık (atık kodu 1705 06)" olduğu belirlenmiştir.

Eluatta $\mathrm{Cl}^{-}, \quad \mathrm{F}^{-}, \mathrm{SO}_{4}^{-2}, \quad$ TÇKM, Mo ve $\mathrm{Sb}$ konsantrasyonlarının, “ADDDY-EK 2" kriterleri tablosunda, II. Sınıf (Tehlikesiz Atık) depolama tesisleri sınır değerlerine uygun olduğu saptanmıştır. Ayrıca, ticari limanlardan alınan DTM'lerin organik madde, PAH, Hidrokarbon ve TOK içerikleri sırasıyla \%2,26-5,01; 0,098$0,732 \mathrm{mg} / \mathrm{kg} ;<65-162 \mathrm{mg} / \mathrm{kg} ;<1.884-9.078 \mathrm{mg} / \mathrm{kg} ;$ balıkçı barınaklarından alınan DTM'lerin <\%0,01-5,84; 0,067$0,155 \mathrm{mg} / \mathrm{kg},<65-82 \mathrm{mg} / \mathrm{kg} ;<1.884-10.708 \mathrm{mg} / \mathrm{kg}$ olarak tespit edilmiştir. Ağır metal içeriklerinin ise ticari limanlardan alınan DTM'lerde balıkçı barınaklarından alınan DTM'lere kıyasla görece daha fazla olduğu gözlenmiştir. $\mathrm{Bu}$ çalışma sonuçlarına göre; DTM'lerin kumlu malzemeler olarak çeşitli ön işlemlerden (tuz giderimi, susuzlaştırma, eleme, organik iyileştirme, $\mathrm{pH}$ ayarı vb.) geçirilmeleri durumunda herhangi bir çevresel riske sebebiyet vermeden zirai/ürün uygulamalarında (iyileştirilmiş yüzey toprağı, beton, karayolu dolgu malzemesi vb.) hammadde olarak faydalı kullanımları açısından umut vaad edebilecekleri düşünülmüştür. Her bir faydalı kullanım alternatifi için teknik ve çevresel uygunluk, yasal zorunluluk, maliyet analizi detaylı ele alınmalıdır.

\section{TEŞEKKÜR (ACKNOWLEDGEMENT)}

Bu çalışma 111G036 no.lu TÜBİTAK KAMAG projesi kapsamında gerçekleştirilmiş olup başta müşteri kurum Çevre ve Şehircilik Bakanlığı, Ulaştırma, Denizcilik ve Haberleşme Bakanlığı ve TÜBİTAK MAM olmak üzere proje ekibine, Dr. Sönmez DAĞLI, Dr. Oltan CANLI, Dr. Yüksel ÇETIIN ve H. Rahmi YILMAZ ve laboratuvar ekibine teşekkür ederiz.

\section{KAYNAKLAR (REFERENCES)}

1. Turkish Statistical Institute. Turkish foreign trade statistics. http:// www.tuik.gov.tr/PreTablo.do? alt_id= 1046. Yayın tarihi Mart 31, 2017. Erişim tarihi Eylül 15, 2017.

2. Directorate General of Merchant Marine, Ministry of Transport, Maritime Affairs and Communications. Freight statistics. https://atlantis.udhb.gov.tr/ istatistik/ istatistik_yuk.aspx. Yayın tarihi Ocak 11, 2017. Erişim tarihi Eylül 15, 2017.

3. Zentar R., Wang D., Abriak N.E., Benzerzour M., Chen W., Utilization of siliceous-aluminous fly ash and cement for solidification of marine sediments, Constr. Build. Mater., 35, 856-863, 2012.

4. Bates M.E., Fox-Lent C., Seymour L., Wender B.A., Linkov, I., Life cycle assessment for dredged sediment placement strategies, Sci. Total Environ., 511, 309-318, 2015.

5. Sheehan C., Harrington J., Management of dredge material in the Republic of Ireland - A review, Waste Manage., 32 (5), 1031-1044, 2012.

6. International Maritime Organization (IMO), The Convention on the Prevention of Marine Pollution by Dumping of Wastes and Other Matter, London Convention, London, United Kingdom, 1972.

7. Türk Yönetmeliği, Çevresel Etki Değerlendirme Yönetmeliği, Resmi Gazete No: 29186, Çevre ve Şehircilik Bakanlı̆̆ 1 , Ankara, Türkiye, 2014.

8. TÜBİTAK MAM, Marine Dredging Applications and Environmental Management of Dredged Materials (DİPTAR), Final Report, Project No: 111G036, TÜBİTAK KAMAG 1007 Project, Kocaeli, Türkiye, 2016.

9. JOCE, Council Directive of 19 November 2008 on Waste, Reference: 2008/98/EC, Off. J. Eur. Communities. L312, 3-30, 2008. 
10. Dubois V., Abriak N.E., Zentar R., Ballivy G., The use of marine sediments as a pavement base material, Waste Manage., 29 (4), 774-782, 2009.

11. OSPAR Commission, JAMP Assessment of the Environmental Impact of Dumping of Wastes at Sea, Biodiversity Series, 433, 2009.

12. LIFE, Methods for Management and Re-use of Polluted Sediments, European Project realized by in vivo, Amsterdam, the Netherlands, (in French) 2002.

13. Grégoire P., Conceptual model for help with multicriterion decision-taking in the framework of the negotiated choice for a marine dredging scenario, Dissertation, University of Artois, France, (in French) 2004.

14. Agostini F., Skoczylas F., Lafhaj Z., About a possible valorisation in cementicious materials of polluted sediments after treatment, Cem. Concr. Compos., 29, 270-278, 2007.

15. Lukens J., National Coastal Program Dredging Policies: An Analysis of State, Territory \& Commonwealth Policies Related to Dredging \& Dredged Material Management Volume I/II, OCRM/CPD Coastal Management Program Policy Series Technical Document 00-02, USA, 2000.

16. Harrington J. and Smith G., Guidance on the Beneficial Use of Dredged Material in Ireland, Report commissioned by Environmental Protection Agency. Cork Institute of Technology, Ireland, 2013.

17. Cai Y., Qiao H., Wang J., Geng X., Wang P., Cai Y., Experimental tests on effect of deformed prefabricated vertical drains in dredged soil on consolidation via vacuum preloading, Eng. Geol., 222, 10-19, 2017.

18. Smith E.R., D'Alessandro F., Tomasicchio G.R., Gailani J.Z., Nearshore placement of a sand dredged mound, Coastal Eng., 126, 1-10, 2017.

19. Riordan J., Murphy J.P., Harrington J.R., Construction and Demolition Waste and Dredge Material as Landfill Liner in Ireland, $1^{\text {st }}$ Middle European Conference on Landfill Technology, The Hungarian Academy of Sciences, Budapest, Hungary, 2008.

20. Krause P.R. and McDonnell K.A., The Beneficial Reuse of Dredged Material for Upland Disposal, HLA Project No. 48881, California, USA, 2000.

21. Yozzo D.J., Wilber P., Will R.J., Beneficial use of dredged material for habitat creation, enhancement, and restoration in New York-New Jersey Harbor", J. Environ. Manage., 73 (1), 39-52, 2004.

22. Reine K., Clarke D., Dickerson C., Fishery resource utilization of a restored estuarine borrow pit: A beneficial use of dredged material case study, Mar. Pollut. Bull., 73 (2), 115-128, 2013.

23. Güzel B., Başar H.M., Güneş K., Yenisoy-Karakaş S., Karakaş D., Tolun L., Assessment of marine dredged materials taken from Turkey's ports/harbors in landscaping, Desalin. Water Treat., 71, 207-220, 2017.

24. Sheehan C., Harrington J.R., Murphy J.D., A technical assessment of topsoil production from dredged material, Resour. Conserv. Recycl., 54 (12), 1377-1385, 2010.

25. Zentar R., Dubois V., Abriak N.E., Mechanical behaviour and environmental impacts of a test road built with marine dredged sediments, Resour. Conserv. Recycl., 52, 947-954, 2008.

26. Xu Y., Yan C., Xu B., Ruan X., Wei Z., The use of urban river sediments as a primary raw material in the production of highly insulating brick, Ceram. Int., 40, 8833-8840, 2014.

27. Cappuyns V., Deweirt V., Rousseau S., Dredged sediments as a resource for brick production: Possibilities and barriers from a consumers' perspective, Waste Manage., 38, 372-380, 2015.

28. Qi Y., Dai B., He S., Wu S., Huang J., Xi F., Ma Y., Meng M., Effect of chemical constituents of oxytetracycline mycelia residue and dredged sediments on characteristics of ultra-lightweight ceramsite, J. Taiwan Inst. Chem. Eng., 65, 225-232, 2016.

29. Haurine F., Cojan I., Bruneaux M.-A., Development of an industrial mineralogical framework to evaluate mixtures from reservoir sediments for recovery by the heavy clay industry: Application of the Durance system (France), Appl. Clay Sci., 132-133, 508-517, 2016.

30. Peng X., Zhou Y., Jia R., Wang W., Wu Y., Preparation of non-sintered lightweight aggregates from dredged sediments and modification of their properties, Constr. Build. Mater., 132, 9-20, 2017.

31. Liao Y.C., Huang C.Y., Chen Y.M., Lightweight aggregates from water reservoir sediment with added sodium hydroxide, Constr. Build. Mater., 46, 79-85, 2013.

32. Ozer-Erdogan P., Basar H.M., Erden I., Tolun L., Beneficial use of marine dredged materials as a fine aggregate in ready-mixed concrete: Turkey example, Constr. Build. Mater., 124, 690-704, 2016.

33. Said I., Missaoui A., Lafhaj Z., Reuse of Tunisian marine sediments in paving blocks: Factory scale experiment, J. Cleaner Prod., 102 (3), 66-77, 2015.

34. Wang L., Yeung T.L.K., Lau A.Y.T., Tsang D.C.W., Poon C.S., Recycling contaminated sediment into ecofriendly paving blocks by a combination of binary cement and carbon dioxide curing, J. Cleaner Prod., 164, 1279-1288, 2017.

35. Kang G.O., Tsuchida T., Kim Y.S., Strength and stiffness of cement-treated marine dredged clay at various curing stages, Constr. Build. Mater., 132, 71-84, 2017.

36. Chikouche M.A., Ghorbel E., Bibi M., The possibility of using dredging sludge in manufacturing cements: Optimization of heat treatment cycle and ratio replacement, Constr. Build. Mater., 106, 330-341, 2016.

37. Lafhaj Z., Saliceto A., Cohen S.L., Coudray Y., Huynh T.T., Le Guen B., Anguoni F., The use of the Novosol process for the treatment of polluted marine sediment, J. Hazard. Mater. 148, 606-612, 2007.

38. Zentar R., Abriak N.E., Tran N.T., Characterisation and impact study on the environment of sediments dredged in the North of France, Revue Paralia, 2, 4.13-4.24, 2009.

39. Bel Hadj Ali I., Lafhaj Z., Bouassida M., Said I., Characterization of Tunisian marine sediments in Rades and Gabes Harbors, Int. J. Sediment Res., 29 (3), 391401, 2014. 
40. Shahri Z. and Chan C-M., On the characterization of dredged marine soils from Malaysian waters: Physical properties, J. Environ. Pollut., 4 (3), 1-9, 2015.

41. Demirel Y. and Çağlar Y., Recovery of phosphogypsum waste in economy as building material, Journal of the Faculty of Engineering and Architecture of Gazi University, 30 (4), 743-750, 2015.

42. Özkan Ö., Properties of mortars containing waste bottle glass and blast furnace slag, Journal of the Faculty of Engineering and Architecture of Gazi University, 22 (1), 87-94, 2007.

43. Aruntaş H.Y., The potential usage of fly ash in construction sector, Journal of the Faculty of Engineering and Architecture of Gazi University, 21 (1), 193-203, 2006.

44. Özüyağlı A., Mehmetalioğlu C., Özsoy M., Akınc1 A., Investigation of mechanical properties of GFRP pipe production waste filled PVC matrix composites, Journal of the Faculty of Engineering and Architecture of Gazi University, 31 (2), 465-472, 2016.

45. Durmuş G., Şimşek O., Dayı M., The effects of coarse recycled concrete aggregates on concrete properties, Journal of the Faculty of Engineering and Architecture of Gazi University, 24 (1), 183-189, 2009.

46. Duyuşen-Güven E., Akıncı G., Gök G., Chemical fractionation and transfer of $\mathrm{Cr}, \mathrm{Cu}, \mathrm{Zn}$ and $\mathrm{Ni}$ in grass grown soil amended with tannery sludge compost, Journal of the Faculty of Engineering and Architecture of Gazi University, 31 (3), 589-596, 2016.

47. Topal H., Plasma gasification technology for solid waste disposal, Journal of the Faculty of Engineering and Architecture of Gazi University, 30 (4), 733-741, 2015.

48. Elcik H. and Çakmakcı M., Microalgae production and biofuel from microalgae, Journal of the Faculty of Engineering and Architecture of Gazi University, 32 (3), 795-820, 2017.

49. Dindar E., Cihan N., Topaç-Şağban F.O., Başkaya H.S., Fractionation of soil organic nitrogen species in soils contaminated with waste mineral oil, Journal of the Faculty of Engineering and Architecture of Gazi University, 32 (3), 767-775, 2017.

50. Eker G., Spatial variations of polycyclic aromatic hydrocarbons (PAHs) concentrations in olive grove area soils in Bursa, Journal of the Faculty of Engineering and Architecture of Gazi University, 32 (2), 607-616, 2017.

51. Standard Method (SM), Standard Methods for the Examination of Water and Wastewater, 22 ${ }^{\text {nd }}$ edn, APHA/AWWA/Water Environment Federation, Washington, USA, 2012.

52. Beijerinck M.W. Le photobacterium luminosum, bact'erie lumineuse de la Mer du Nord, Arch N'eerl des Sci Exact et Nat., In French, 23, 401-415, 1889.

53. TS EN 12457-4 (Türk Standard1), Atıkların Nitelendirilmesi-Katıdan Özütleme Analizi-Bölüm 4: Sıvı Katı Oranı 10 lt/kg Olan ve Partikül Boyutu 10 mm'den Küçük, Yüksek Katı Madde Muhtevalı Malzemeler için Tek Aşamalı Parti Deneyi, Türk Standartları Enstitüsü, Ankara, Türkiye, 2004.
54. Türk Yönetmeliği, Atık Yönetimi Yönetmeliği, Resmi Gazete No: 29314, Çevre ve Şehircilik Bakanlığ1, Ankara, Türkiye, 2015.

55. Jones R.A. and Lee G.F., The Significance of Dredging and Dredged Material Disposal as a Source of Nitrogen and Phosphorus for Estuarine Water, In: Estuaries and Nutrients, Clifton (NJ): Humana Press, NJ, USA, 517530, 1981.

56. Price C., Brannon J., Yost S., Sanchez F., Thibodeaux, L., Valsaraj, K., Ravikrishna, R., Volatile Losses from Resuspended Dredged Material, Environmental Effects of Dredging Technical Note EEDP-02-28, U.S. Army Engineer Research and Development Center, Vicksburg, MS, 2001.

57. Environment Agency, Hazardous Waste: Interpretation of the Definition and Classification of Hazardous Waste, Technical Guidance WM2, London, United Kingdom, 2011.

58. Köthe H. and Boer P., Dutch-German Exchange (DGE) on Dredged Material - Part 1-Dredged Material and Legislation, The Hague and Bonn, 2003.

59. Casper S.T., Regulatory frameworks for sediment management, sustainable management of sediment resources: Sediment management at the river basin scale, Nat. Resour., 55-81, 2008.

60. Türk Yönetmeliği, Atıkların Düzenli Depolanmasına Dair Yönetmelik, Resmi Gazete No: 27533, Çevre ve Şehircilik Bakanlığı, Ankara, Türkiye, 2010.

61. Lloyd J.W. and Heathcote J.A., Natural Inorganic Hydrochemistry in Relation to Groundwater, Clarendon Press, Oxford, England, 1985.

62. Morris P.H. and Wong L., Modification of Dredged Sediments to Produce Useful Product by Heating to High Temperatures: Literature Review, CRC for Sustainable Tourism Pty Ltd., Australia, 2005.

63. Davidov R.B., Harman G., Landess S., Muir W., Scott D., Swensen P. and Petzrick P., Innovative Reuse of Dredged Material, Report to the Executive Committee of Maryland's Dredged Material Management Program, USA, 2007.

64. Sheehan C., Harrington J.R., Murphy J.D., An environmental and economic assessment of topsoil production from dredge material, Resour. Conserv. Recycl., 55 (2), 209-220, 2010.

65. Türk Standard1, TS 706 EN 12620+A1, Beton Agregaları, Türk Standartları Enstitüsü, Ankara, Türkiye, 2009.

66. Karayolu Teknik Şartnamesi (KTŞ), Yol Altyapısı, Sanat Yapıları, Köprü ve Tüneller, Üstyapı ve Çeşitli İşler, Karayolları Genel Müdürlüğü, Ankara, Türkiye, 2013.

67. Kim D., Lee J., The effects of chloride on durability of concrete mixed with sea sand, US-China Educ. Rev. A, 3 (5), 325-331, 2013.

68. Rozière E., Loukili A., El Hachem R., Grondin F., Durability of concrete exposed to leaching and external sulphate attacks, Cem. Concr. Res., 39 (12), 1188-1198, 2009. 